\title{
Corporaciones públicas multinacionales para el desarrollo y la integración
}

MARCOS KAPLAX ha sido profesor de la Facultad de Ciencias Económicas de Buenos Aires, e investigador en el Centro de Investigación Aplicada de la Universidad de Buenos Aires; profesor de Politica Económica en la Escuela de Derecho de la Universidad de Chile en Valparaiso; profesor-investigador en el Comité Interdisciplinario de Desarrollo Urbano (Santiago de Chile); profesor-investigador en el Instituto de Estudios Internacionales de la Universidad de Chile. Actualmente es profesor en la Escuela de Ciencia Politica y Administración Pública de la flacso. Sus principales publicaciones incluyen: Economia y Politica del Petróleo Argentino (1939-1956), 1957; La crisis del Radicalismo, 1957, Politica y Vida Colidiana, 1960; Paises en Desarrollo y Empresa Pública, 1965; Problemas Estructurales de América Latina $y$ Planificación para el Desarrollo, 1968 (en colaboración con Raúl Basaldúa); Problemas del Desarrollo y de la Inlegración de América Latina, Ig68

\section{UN MODELO DE INTEGRACIÓN EN CRISIS}

Este trabajo. intenta trazar un balance de la integración a través de la Asociación Latinoamericana de Libre Comercio (ALALC), y proponer la fórmula de las corporaciones públicas multinacionales como uno de los agentes de ese proceso.

La integración latinoamericana, como toda experiencia análoga, debe cumplirse a la vez entre espacios de vasta dimensión agregada, y entre una variedad de grupos nacionales estructurados en sistemas socioeconómicos, institucionales, politicos y culturales; todo ello como parte de un proceso general en el cual los aspectos y niveles interactúan, se interpretan y condicionan reciprocamente.

Un balance del camino recorrido hasta la fecha permite afirmar que ninguna de las dos experiencias de integración latinoamericana en marcha -la Asociación Latinoamericana de Libre Comercio y el Mercado Común Centroamericano- poseen un dinamismo inherente que garantice automáticamente un progreso ininterrumpido. 
Marcos Kaplan / Corporaciones públicas multinacionales para el desarrollo...

En lo que a la ALALC respecta - y a ella me restrinjo por ser el proyecto de mayor envergadura $y$ trascendencia en la región-, su génesis $y$ progreso, el modelo que encarna, no son resultado de una acción delibe: rada y consecuente, sino más bien subproducto en gran medida casual de reacciones empiricas ante las crisis conyunturales y estructurales que viene sufriendo América Latina y ante algunas de sus consecuencias. Un sincretismo precario de teoria abstracta y de pragmatismo limitado y de corto plazo parece signar desde la partida la experiencia de la ALALC, como surge de una somera enumeración de los motivos reales y de los argumentos doctrinarios que pretenden explicarla y justificarla, resumibles del modo siguiente.

\section{Motivaciones reales y argumentos doctrinanos ${ }^{1}$}

Cambios en los determinantes y condicionantes del modelo tradicional de crecimiento dependiente, hacia afuera y en superficie: caida de la demanda y precios de las exportaciones, deterioro de los términos del intercambio; cambio de orientación y debilitamiento del flujo internacional de capitales privados; endeudamiento creciente.

Necesidad de mecanismos que permitan superar dificultades de las balanzas de pagos (escasez, control, convertibilidad de divisas), compensando saldos monetarios bilaterales, multilateralizando su uso, e incrementando el comercio intrazonal.

Problemas de la industrialización substitutiva de importaciones, no integrada ni reforzada por cambios estructurales, que determina fuertes necesidades de importaciones frente a exportaciones menguantes y a un creciente endeudamiento, y obliga a proseguir el proceso en un sentido de mayor autoabastecimiento de materias primas, productos intermedios $y$

'Entre la vasta bibliografia suscitada por la integración latinoamericana, puede citarse: Integración de América Lalina-Experiencias y perspectivas. Edición preparada por Miguel S. Wionczek, Fondo de Cultura Económica, Buenos Aires-México, 1964; Hacia la Integración Acelerada de América Latina F. de C. E., I965; Factores para la Inlegración Latinoamericana. Edición preparada por el Banco Interamericano de Desarrollo. $F$. de c. E., 1966; Instituto para la Integración Latinoamericana, La Integración Latinoamericana-Siluación y Perspectivas, Buenos Aires, 1965; Sidney Dell, Experiencias de la Integración Económica en América Latina, c.E.M.L.A., México, I966; Sociedad Interamericana de Planificación, Hacia una Politica de Integración para el Desarrollo de la América Latina, San Juan, Puerto Rico, 1967. 
E S T L D I O S I $\therefore$ T E R $\therefore$ A C I O $\therefore A$ L E S

bienes de capital. Dificultad e imposibilidad de marchar hacia la industrialización integrada y el desarrollo continuo y autosostenido, en condiciones de mercados actuales insuficientes por dimensión fisica y demográfica, por la estructura socioeconómica, ocupacional y de ingresos, y por la inestabilidad externa.

En consecuencia, la integración comienza a ser concebida como una especie de base y de marco general que posibilite:

Mercados adicionales para la producción primaria y para la industrial, suficientemente generalizados, amplios y permanentes para permitir una escala operativa de gran magnitud e inversiones cuantiosas, a largo plazo y de rentabilidad mediata.

Superación del binomio: "producciones paralelas en mercados insuficientes-capacidad instalada ociosa".

Aprovechamiento reciproco de complementariedades.

Surgimiento de nuevas actividades, ramas, empresas y tecnologias, que cada pais por si solo no puede intentar.

Optimización en: el empleo de factores; las economias de escala; la localización de nuevas inversiones respecto de los insumos; el impulso tecnológico y cientifico; la movilización de cuadros y la especialización avanzada de tareas; la mayor racionalización del esfuerzo humano sin baja de la ocupación.

Continuidad ininterrumpida del proceso de substitución de importaciones.

Elevación de la inversión, de la productividad y del consumo.

Un papel decisivo en el surgimiento y aplicación del modelo vigente de integración lo tiene el temor a las repercusiones disruptivas que el atraso y el estancamiento económico pueden producir en condiciones de explosión demográfica, impacto del éfecto-demostración y de la multiplicación de expectativas crecientes, y sus secuelas de tensiones y conflictos sociales, ideológicos y politicos. El desafio cubano es percibido como la encarnación del peligro revolucionario, al que no se considera funcional combatir solamente con medidas represivas. Es bajo el signo de un conservantismo modernizante que nace y comienza a tener explicación el modelo oficial de integración, como lo evidencian sus caractcristicas que más adelante se indican.

La integración no es presentada como opción excluyente del desarrollo nacional, ni de una mayor integración en el mercado mundial, sino como prerrequisito para la adición de posibilidades. Debe facilitar y promover 
Marcos Kaplan / Corporaciones públicas multinacionales para el desarrollo...

un crecimiento interno más rápido y diversificado, la modernización, la integración nacional, la movilización de grupos sociales dinámicos. Puede permitir la acumulación de las ventajas del mercado nacional y de los mercados de los paises que coparticipan en el proceso, al tiempo que crear condiciones para un mayor acceso a los mercados de los paises avanzados. La integración en un gran mercado regional adoptaria asi las ventajas tradicionalmente atribuidas a la división internacional del trabajo, sin los inconvenientes que para los paises en desarrollo ha traido la aplicación irrestricta de aquél, sobre todo en lo referente a la competencia industrial de los paises avanzados.

La integración regional es particularmente necesaria $y$ viable para paises que tienen comunidad de origen e historia, de proximidad geográfica, de composición étnica, de estructuras socioeconómicas, políticas y culturales, y de obstáculos externos al progreso. Paises separados por las vicisitudes del pasado y por las manipulaciones de algunas potencias, y que pretenden ser, no ya objetos pasivos sino sujetos autónomos de su propia historia y de la politica mundial. La integración implica pues la creación de un bloque unificado que fortalezca la posición internacional, la capacidad de negociación y la autonomia real de los paises latinoamericanos. Estas consideraciones son generadas y reforzadas por ciertas circunstancias y tendencias de tipo internacional, como las siguientes.

Desde hace décadas, el sistema internacional marcha hacia la organización de grandes espacios económicos. Estados Unidos y la Unión Soviética, el Mercado Común Europeo, el comecos, China, operan para América Latina como ejemplo y desafio. Le han revelado la vigencia creciente de las grandes comunidades y espacios de dimensión continental y subcontinental, como forma actual para todo un futuro de duración imprevisible, de organización económica supranacional. Le han revelado también, por contraste, que cada Estado latinoamericano es incapaz por si solo de ofrecer los recursos y el cuadro sociopolitico e institucional que se requiere para promover y preservar un grado adecuado de desarrollo; y que se impone la creación y consolidación aceleradas de una macrosociedad latinoamericana y de neo o supranacionalismo de dimensión regional.

Un aspecto decisivo del impacto internacional está constituido por el creciente interés que hacia la integración han comenzado a desplegar las 
grandes empresas privadas y el gobierno de los Estados Unidos ${ }^{2}$. A una primera actitud de desconfianza y hostilidad hacia la ALALC, ha sucedido otra de adaptación y aprovechamiento. El modelo propuesto de desarrollo e integración ofrece posibilidades incalculables para las inversiones privadas norteamericanas y para la consolidación definitiva de un poder hegemónico de los Estados Unidos sobre la región. La supresión de barreras intrarregionales y la tarifa común contra terceros implicará la posibilidad de operar sobre un mercado unificado de centenares de millones de habitantes, precisamente adecuado y tentador para macrounidades norteamericanas que ya operan o pueden llegar a crear empresas de dimensión óptima, las más capitalizadas y dinámicas. Tales empresas podrán disfrutar posibilidades considerables de mercados ampliados y estabilizados, economias de escala y reducción de costos. Estarán en mejores condiciones de eliminar, o de subordinar a su constelación, a los competidores locales o europeos. Podrán organizarse y funcionar en base a un nuevo esquema de división y especialización del trabajo, por ramas $y$ por regiones, en escala continental. El proceso de integración tiende a estimular el aumento de la dimensión de las empresas y de sus establecimientos, y a favorecer la concentración acelerada, multiplicando monopolios y eligopolios en los sectores clave. Contribuye a crear, multiplicar o fortalecer centros de poder internacional, verdaderas superpotencias exteriores a la región, que tomarán cada vez más decisiones básicas y trascendentales para la estructura y la dinámica de cada pais latinoamericano y de la región en su conjunto (inversiones, locálización, tecnologia, producción y ocupación, ingresos, comercio exterior, grado de integración interna de las economias nacionales, tipos de especialización, esquemas de equilibrio o de desequilibrio entre paises, áreas y grupos sociales).

La hegemonia de las macroempresas norteamericanas significa la imposición de un modelo de desarrollo y de integración en que aquéllas tendrán el papel fundamental y recogerán el grueso de los beneficios, lo que implicará reservar para América Latina un destino de apéndice

${ }^{2}$ Sobre las actitudes y politicas de las empresas privadas norteamericanas y del Gobicrno de Estados Unidos, ver Marcos Kaplan, "Problemas del Desarrollo y de la Integración de América Latina", edeval, Valparaiso, 1967 ; Victor Urquidi, Viabilidad Económica de América Latina, F. de C. E., 1962; Helio Jaguaribe, "Inversiones Extranjeras y Desarrollo Nacional", en Revista Desarrollo Económico, Buenos Aires, Vol. 6, N.os 22-23; Osvaldo Sunkel, "Politica Nacional de Desarrollo y Dependencia Externa", en Revista Estudios Internacionales, año i, $\mathrm{N}^{\circ} 1$, abril de 1967 , Santiago de Chilc. 
Marcos Kaplan / Corporaciones públicas multinacionales para el desarrollo...

subordinado de los Estados Unidos. Dado el peso específico y la influencia aplastante de los consorcios norteamericanos, el apoyo ilimitado que ellos reciben del gobierno de Estados Unidos, la indentificación que se proclama entre el statu quo de América Latina y los intereses de seguridad de aquel pais, todo lleva al ejercicio de un estricto control externo y de una rigurosa supervisión sobre el tipo de desarrollo, la política económica, la estructura de poder y los procesos sociales de la región. Alianza para el Progreso, integración regional y aparatos y operativos para la lucha militar contra la subversión pasan a ser visualizados como partes inseparables de una estrategia única. Los Estados latinoamericanos pueden ir perdiendo gran parte de sus funciones políticas, especialmente las relativas a la orientación del proceso socioeconómico. La nación como realidad sustancial y operativa puede desdibujarse cada vez más en su contenido y vigencia, y la idea misma del nacionalismo volverse obsoleta.

Esta implicaciones posibles, y en gran parte ya actuales, del modelo de integración propuesto, que desde el lado latinoamericano son visualizables como peligros, actúan desde la perspectiva de los consorcios y del gobierno de Estados Unidos como motivos de interés y apoyo hacia dicho modelo.

\section{Las realizaciones}

La alalc, creada por el Tratado de Montevideo, de febrero de ig6o, pese a sus limitaciones de origen y a las fallas que se han ido revelando, ha tenido aspectos y resultados positivos para la región. Constituye el primer paso de una experiencia nueva y riesgosa, tendiente a integrar países disimiles por su estructuración y grado de desarrollo, en condiciones mundiales y regionales especialmente dificiles. Pese a todo, y contra previsiones pesimistas muy generalizadas, se logra concretar un acuerdo, limitado y discutible, pero acuerdo al fin. Con limitaciones y vicisitudes, ALALC perdura ya durante más de ocho años.

ALALC ha funcionado como marco para la realización de negociaciones de liberación comercial, a través de un mecanismo institucional destinado a solucionar problemas y obstáculos. El intercambio intrazonal hace progresos significativos. Se suscriben y entran en vigencia dos acuerdos de complementación industrial. Se adopta la Nomenclatura 
Arancelaria de Bruselas como base común para la presentación de estadisticas, para la realización de negociaciones y para la interpretación de las concesiones otorgadas. Se establecen criterios para determinar el origen real de las mercaderías involucradas en el comercio zonal, a efectos de la aplicabilidad de las concesiones y para reducir el peligro del fraude a través de maniobras de reexportación. Se celebran reuniones sectoriales en gran número, y se constituyen comisiones especiales y grupos de trabajo para tratar los distintos aspectos de la integración. Es elaborado un sistema estadistico sobre bases uniformes aplicables al análisis del comercio intrazonal. Los mecanismos de la ALALC favorecen el acercamiento y el mutuo conocimiento de los empresarios de la región y cierta mayor participación de ellos en el proceso. La idea y la problemática de la integración reciben alguna divulgación en la opinión pública de los paises implicados.

\section{Insuficiencias y obstáculos ${ }^{3}$}

Establecido en general el haber positivo de la integración, cabe señalar también, para completar el cuadro y posibilitar el balance, las insuficiencias verificadas hasta la fecha, los obstáculos que se oponen a su progreso. Se impone examinar a partir de qué realidades y con qué alcances e instrumentos ha comenzado a vivir la ALALC.

A diferencia del Mercado Común Europeo, la tentativa integradora de América Latina parte de un atraso secular que tiende a agravarse en el momento mismo de empezar y que la paraliza para intentar precisamente la superación de ese atraso. El retardo histórico y el consiguiente subdesarrollo de América Latina proporcionan a la vez las motivaciones y los obstáculos para la integración.

Ello se manifiesta ante todo en una contradicción básica entre la región a integrar y las naciones que la componen. Estas despliegan una considerable heterogeneidad, que las divide por lo menos en tres categorias: "Tres Grandes", un grupo intermedio, y los países de menor desarrollo.

${ }^{3}$ Ver: Marcos Kaplan, Problemas del desarrollo... cit.; Jorge Graciarena, Poder $y$ Clases Sociales ẹn el Desarrollo de América Latina, Paidós, Buenos Aires, 1967, pp. 213 y ss.; $y$ bibliografia citada en nota 1. Esta problemática fue ampliamente discutida en el Seminario de Arica, enero de 1968, organizado por el Instituto de Estudios Internacionales de la Universidad de Chile, ver Revista Estudios Internacionales, $\mathrm{N}^{\circ} 5$. 
Marcos Kaplan / Corporaciones públicas multinacionales para el desarrollo...

Tienen enormes diferencias y desniveles entre si, en cuanto a bases geográficas, trayectorias históricas, etapa de desarrollo, estructuras socioeconómicas, grado de industrialización, tasas de salarios, niveles de vida, situaciones de mercado, politicas concretas e instrumentos disponibles (de tipo impositivo, aduanero, monetario, cambiario, crediticio). Todo ello crea, durante el proceso integrador, graves divergencias de aspiraciones y exigencias de trato privilegiado por parte de cada pais participante.

A ello se agrega la circunstancia de ser sus economias centrifugas, más unidas a Europa y Estados Unidos que entre si mismas; no complementarias sino mutuamente competitivas; separadas por distancias y obstáculos geográficos insuperables; carentes de la infraestructura que facilite mayores relaciones intrarregionales. Las diferencias de regimenes politicos, de acción diplomática, de pautas culturales, y de orientaciones ideológicas, completan y agravan el cuadro. América Latina carece de tradiciones e instrumentos de cooperación económica multilateral. No existe un sentimiento de solidaridad regional tan fuerte como para que se trasciendan los particularismos nacionales. No existe tampoco una nación suficientemente dotada y dispuesta para promover y capitanear por si sola la empresa; ni acuerdo entre los "Tres Grandes" de la Zona (Argentina, Brasil, México) para asumirla conjuntamente.

Esta situación refuerza la resistencia al cambio, opuesta por la estructura socioeconómica tradicional $y^{\prime}$ por los grupos identificados con aquélla, que se oponen a toda modificación, temen los efectos que la integración podria producir sobre sus intereses particulares, y/o no creen en la posibilidad de beneficiarse con aquélla. Ello va acompañado por una debilidad relativa de los sectores que eventualmente deberian impulsar e imponer el avance y profundización del proceso integrador. Las fuerzas opuestas o favorables a la integración operan tanto en el plano interno de cada pais y de la zona como en el nivel internacional.

Los sectores y grupos opuestos - pasiva o activamente- a la integración parecen ser:

Los vinculados a la estructura tradicional, o a ramas estáticas o vegetativas, pero productivas o deficitarias; especialmente:

productores agropecuarios, exportadores e importadores, intermediarios; pequeña y mediana industrias, adormecidas en el proteccionismo inicial; burocracia pública y privada de viejo tipo; 
las Fuerzas Armadas, que ven en la integración un peligro posible para la soberania nacional en el sentido tradicional, y para su propio predominio dentro de cada pais;

partidos politicos que responden a los grupos tradicionales, y/o se hallan inspirados por una variante particular del desarrollismo (v. gr. el Frondizismo en la Argentina); y los pertenecientes a la Vieja Izquierda (La Nueva Izquierda parece aceptar la necesidad de la integración, bajo la forma revolucionaria socializante).

Empresas extranjeras con inversiones en las actividades primarias y sin participación en el proceso industrial interno.

Paises más pequeños, o de menor desarrollo relativo, que temen la posible falta de reciprocidad en la integración y el peligro de mayores desigualdades o de absorción, y adoptan una actitud marginal y expectante; y paises "grandes" que visualizan la integración como incompatible e innecesaria respecto a lo que consideran posibilidades propias de desarrollo nacional por separado (Argentina).

Los sectores y grupos promotores de la integración, o no totalmente opuestos a ella, parecen ser:

Intelectuales, universitarios, técnicos, funcionarios nacionales e internacionales.

Partidos y gobiernos inspirados por una cierta concepción desarroHlista (v. gr. Democracia Gristiana de Chile, Partido Revolucionario Institucional de México).

Instituciones técnicas y financieras internacionales (CEPAL, BID).

Sectores vinculados a ramas $y$ organizaciones modernas $y$ dinámicas de producción de bienes y servicios para el mercado interno y para la exportación "no tradicional" (siderurgia, maquinaria, consumo duradero).

Algunos de los paises de mayor tamaño y más alto grado de desarrollo (Mléxico, Brasil).

Algunos paises avanzados y sus consorcios internacionales, interesados en un tipo determinado de crecimiento e industrialización para América Latina (sobre todo Estados Unidos, por las razones y con las calificaciones arriba señaladas).

En el balance de fuerzas de contenido, signo e intensidad diferentes, las opuestas a la integración parecen prevalecer sobre las que podria suponerse favorables — potencial o actualmente- a la misma. Particular- 
Marcos Kaplan / Corporaciones públicas multinacionales para el desarrollo...

mente notable resulta la actitud de ignorancia, indiferencia o pasividad que, salvo raras excepciones, exhiben el empresario industrial, las capas medias y el sindicalismo obrero.

Esta inexistencia o debilidad de las fuerzas sociales activamente favorables a la integración, que la convierte de hecho en una especie de drama abstracto sin protagonistas de carne $y$ hueso, se refleja en la actuación de los partidos politicos, y del Estado, en el clima colectivo que envuelve el proyecto de integración, y en las caracteristicas del propio modelo propuesto.

El tipo particular de desarrollo que ha tenido lugar en la America Latina contemporánea se ha traducido en una superposición de fuerzas y formas socioeconómicas, politicas, ideológicas y culturales, correspondientes a etapas históricas diferentes, y por consiguiente, en estructuras sociales diversificadas, heterogéneas y altamente contradictorias. Ello contribuye a que, en lo politico, se vean trabados y perturbados la formulación de objetivos y el despliegue de forma de acción racional. Se dificulta el logro de un consenso suficientemente amplio para la determinación clara y la implementación efectiva de grandes tareas y fines nacionales. El número y diversidad de las fuerzas correspondientes a fases, estructuras sociales $y$ bases regionales tan diversas y conflictivas, multiplican las divergencias $y$ los antagonismos, las opciones irreductibles y las alianzas incongruentes; desembocan en la incoherencia, el empate y la parálisis; impiden la clara formulación de los problemas y el logro de decisiones realmente resolutorias, sobre todo en lo referente a los problemas básicos del desarrollo económico y el cambio social. Los partidos politicos se muestran incapaces de aglutinar y expresar congruentemente $y$ en términos de acción a las diversas clases, fracciones y grupos. Casi ninguno de ellos exhibe una preocupación efectiva y operante para la integración, ni constituye a ésta en una de sus principales motivaciones intelectuales y emocionales. En las mejores hipótesis, el apoyo de algunos partidos a la integración suele tener un carácter retórico; no llega a ser un compromiso prioritario y militante con el proyecto, traducido en actividades políticas sistemáticas y como parte de un modelo general de transformaciones internas.

Este déficit de las clases y de los partidos respecto a la integración contribuye a que ella carezca de calor popular y consenso público favorable, e incide sobre la actitud y la conducta de los Estados latinoamericanos al repecto 4 .

${ }^{4}$ Sobre la naturaleza $y$ las fallas estructurales del Estario en América Latina, ver: 
El Estado de los países latinoamericanos ha heredado y conserva una maquinaria anticuada $y$ una tradición de leseferismo liberal, que no lo prepara ni capacita para asumir un número creciente de nuevas $y$ complejas tareas, y le presentan su intervencionismo como anormal $y$ transitorio. Es en general el Estado de un capitalismo dependiente, de desarrollo desigual y combinado, que parece entrar en decadencia antes de madurar. Tiende a expresar los intereses de las clases dominantes, nacionales y extranjeras; pero debe tener también en cuenta la existencia de fuerzas y presiones correspondientes a sociedades que en muchos casos son ya relativamente complejas y diversificadas.

Las intervenciones y empresas del Estado ven refractadas y modificadas sus actividades, y las consecuencias previstas de las mismas, por una estructura y un ambiente desfavorables $u$ hostiles al desarrollo, al cambio social, a la modernización y a la racionalidai, y por la penetración e influencia de grupos privados. Manifestaciones importantes de este marco condicionante negativo son: la búsqueda de la ayuda y de la dependencia externas como substituto del impulso y la iniciativa interiores; la supremacia, afirmada con ribetes casi mitológicos, de la propiedad, la iniciativa y la ganancia privadas; el conservantismo y la rigidez del sistema de estratificación social y de poder. En virtud de la crisis de hegemonia que afecta a las sociedades latinoamericanas, ninguna clase o fracción domina total y exclusivamente el Estado, ni lo utiliza en función de una estrategia definida y coherente. Todas las clases, capas y estratos pujan sobre y dentro del Estado, en mayor o menor grado y con variable fuerza, para lograr satisfacción a sus intereses sectoriales; en consecuencia, la acción de aquél parece convertirse a menudo en una mera resultante inestable del juego de presiones múltiples. Los consorcios monopolistas y gobiernos extranjeros - sobre todo norteamericanos-, y los grupos nacionales que con aquéllas se entrelazan, despliegan una hostilidad sistemática hacia el intervencionismo y la regulación del Estado, sin dejar de utilizar a éste para sus fines particulares, penetrándolo con sus representantes, sus influencias y controles, su ideologia. La burguesia

Marcos Kaplan, Problemas del Desarrollo..., cit., y Problemas Estructurales de América Latina y Planificación para el Desarrollo (en colaboración con Raúl O. Basaldúa), Omeba, Buenos Aires, 1968; Jacques Lambcrt, Amerique Latine-Structures Sociales et Institutions Politiques, Presses Universitaires de France, Paris, 1963; Federico G. Gil, Instituciones y Desarrollo Politicu de América Latina, INTAL, Buenos Aires, 1966; Jorge Graciarena, Poder y Clases. .., cit. 
Marcos Kaplan / Corporaciones públicas multinacionales para el desarrollo...

industrial nacional no ha proporcionado al Estado una estrategia, ni tampoco los cuadros, la experiencia empresarial, las pautas de racionalidad y eficacia de que ella misma carece; ha tratado de penetrarlo, influirlo y utilizarlo para el logro de fines inmediatos y restringidos; $y$, como ejemplo notable de falta de conciencia, no ha dejado jamás de combatir un intervencionismo gubernativo sin el cual no podria haber surgido, subsistir ni prosperar. La presión de las capas medias y populares se ha ejercido en gran medida de modo mecánico y externo, 'sin participación directa y activa sobre y en el Estado, o a través de la subordinación y la participación vicaria, populista y burocrática. La multiplicación de presiones sociales y politicas, de sentido divergente y antagónico, ha contribuido a desgarrar, irracionalizar y paralizar la acción del gobierno.

Esta situación básica se ha ido agravando con la combinación de liberalización económica y absolutismo politico. Las sociedades latinoamericanas tienden cada vez más al estancamiento y la rigidez, a la retribución regresiva del ingreso, a la concentración del poder en grupos reducidos, a la frustración de aspiraciones en las capas medias y populares, y al aumento consiguiente de desequilibrios, tensiones y conflictos. Ello se ha reflejado y reforzado a través de un doble movimiento. Por una parte, se ha ido desarrollando un movimiento de liberalización económica, entendida como debilitamiento del aparato del Estado, la inoperancia o supresión de sus poderes y mecanismos de intervención en la vida socioeconómica, de regulación, orientación, promoción y actividad empresarial. Los centros de decisión económica tienden a ser transferidos del Estado a las fuerzas del mercado, o sea las estructuras corporativas, los grupos privados dominantes, tanto nacionales como extranjeros. La estructura tradicional es reforzada, se abren las puertas a la penetración colonialista y al refuerzo de la relación de dependencia y del estancamiento. Por otra parte, aunque de modo ligado y convergente, se va afirmando el absolutismo politico: ilegalización de las fuerzas, movimientos y luchas de cambio social; intensificación de métodos y aparatos represivos; degradación y supresión del sistema politico-juridico liberal (Estado de Derecho, soberania popular, sufragio universal, libertades públicas, controles democráticos). Liberalización económica y absolutismo político se combinan para introducir o reforzar factores de freno, crisis e irracionalidad en la acción del Estado.

Este encuadre general permite ubicar y comprender mejor otros rasgos 
ES T U D I O S I $N$ T ER NA C I O $\therefore$ A L E S

de la actividad gubernamental. El Estado en América Latina carece de precedentes válidos y de una filosofia unificada, actualizada y eficaz, que le permitan definir el carácter, el alcance y los métodos de sus intervenciones y controles. Unos y otros no se producen como expresión y resultado de una deliberada voluntad transformadora y planificadora. Surgen y se mantienen en y por la improvisación, por presión y apremio de sucesos y situaciones conyunturales y de emergencia, que luego resultan más duraderos de lo pensado. Se cumplen con una especie de "mala conciencia" y con una ambigüedad paralizantes, en virtud de las cuales no se utilizan o se utilizan mal los instrumentos de politica económica y los entes empresariales que de todos modos han ido cayendo en sus manos. Las intervenciones no integran un plan; resultan inorgánicas e incoordinadas, contradictorias y desorganizadoras; causan perturbaciones no previstas; chocan entre sí y con otros actos y objetivos del Estado; alimentan la irracionalidad y la anarquia. Este cuadro general se manifiesta y repercute en el modo de actuación $y$ en los resultados del sector público y de sus empresas, de los cuales se hace un uso a la vez indiscriminado, errático y limitado.

El Estado de América Latina, efectivamente, no utiliza, o utiliza mal, el potente resorte que podrian constituir el sector público y sus empresas para el cumplimiento de un proceso de desarrollo. Comienza por tener una posición limitativa y ambigua respecto a su propio papel y al de sus agencias y empresas. Tiende a rechazar la idea de que las esferas básicas y las palancas de comando de la economia deben pertenecer al sector público. Este y las empresas gubernamentales no se han expandido más rápidamente que los entes privados - salvo excepciones por épocas y ramas. El sector público y sus agenciàs duran por inercia resultante de la herencia histórica y del empate de las fuerzas sociales. La acción estatal no tiende a expandir el sector público, a favorecerlo ni a utilizarlo como líder y pionero del desarrollo. El Estado valoriza, privilegia y refuerza el papel y el poder de las grandes empresas privadas, y tiende a reducirse a funciones de regulación minima y de cobertura de las brechas que aquéllas dejan abiertas o abren en la economia y en la sociedad.

Por otra parte, y pese a todo, el Estado no puede imponer el regreso -o el ingreso- a una economia liberal pura. No se compromete tampoco explicitamente con el mantenimiento de una economia mixta; la mantiene de hecho, pero no define precisamente las condiciones de vigencia de 
Marcos Kaplan / Corporaciones públicas multinacionales para el desarrollo... aquélla, ni su propia función dentro de la misma. Rara vez explicita criterios ni fija normas inequivocas de alcance general, para delimitar qué tipo de coexistencia se busca establecer y mantener entre el sector público y el privado; cuál de ellos irá prevaleciendo; en qué ramas existirá competencia entre ambos, o bien exclusividad para uno de ellos solamente. En los casos en que el Estado mantiene su ingerencia o su monopolio en una rama o tipo de empresa, no termina de resolver ni su actividad se orientará hacia tareas productivas propias, o hacia la mera asistencia técnica y financiera de entes privados.

Esta situación de ambigüedad tiene lógicamente un carácter fluctuante e inestable. La coexistencia incierta entre ambos sectores no puede ser nunca mecánica ni perdurar largo tiempo; determina relaciones e influencias mutuas entre ambos sectores, modificaciones reciprocamente inducidas, contradicciones y conflictos, repercusiones politicas e institucionales. Tarde o temprano uno $u$ otro debe prevalecer. La coexistencia, sin embargo, se mantiene, aunque con tendencia al fortalecimiento del sector privado a expensas del público y en detrimento de su paso y eficacia. La caracterización precedente contribuye a explicar que se hạlle limitada la capacidad del Estado en América Latina para operar como agente eficaz del desarrollo y de la integración. Las acciones valerosas, impactantes y a largo plazo, requeridas para impulsar la integración, suelen ser rechazadas o postergadas por gobiernos poco representativos; no sustentados por una sólida trama de fuerzas socioeconómicas y politicas activamente comprometidas con el desarrollo y la integración ni —en muchos casospor una plena unidad nacional; presionados por grupos minoritarios; de precaria base politica; absorbidos por dificultades inmediatas que impiden la visión clara y la decisión certera y rápida. La adhesión del Estado al sistema y a la ideologia del laissez faire, su tendencia persistente a intervenir para mantener y reforzar uno y otra, se traducen en una autoabdicación de sus posibilidades, poderes e instrumentos de control, regulación y acción transformadora, $y$ en la consiguiente incapacidad para proporcionar una ideologia, orientaciones valorativas, opciones definidas ante las múltiples alternativas, planes y programas, que posibiliten la existencia $y$ viabilidad de una estrategia para el desarrollo y la integración. Estos quedan librados a la dinámica del mercado y de los intereses privados más organizados y dominantes, que se desinteresan de aquellas tareas, o bien le imprimen su signo particular y limitativo. Las exigencias y actividades 
relacionadas con la integración suelen por añadidura reservarse a funcionarios de segunda categoria, con poca o nula capacidad de decisión.

Para la experiencia de integración en curso a través de la Alalc se ha elegido y presentado un solo modelo. Ello implica desde el comienzo la exclusión aprioristica de opciones fundamentales ante una serie de alternativas, y una postura ideológica que subyace bajo la apariencia de una neutralidad tecnocrática. Este modelo, según se dijo, surge y opera como respuesta al peligro revolucionario, bajo el signo de un reformismo conservador. Aparece como una especie de panacea universal que, por si misma y de modo automático, promueve el desarrollo, la modernización y la autonomia de América Latina; solamente requiere cambios restringidos y prefijados; permite el mantenimiento de la estabilidad social, de las actuales estructuras clasistas, de la constelación de poder vigente, y de la ubicación tradicional de la región dentro del bloque bajo hegemonia de los Estados Unidos. La integración es concebida como condición necesaria y suficiente del desarrollo, o bien como parte de una visión muy peculiar de este último, a la que es útil dedicar alguna atención (Esta concepción del desarrollo es paradójicamente compartida por partidarios y enemigos de la integración $)^{5}$.

El enfoque básico de que se parte peca de superficialidad y mecanicismo. En primer lugar, asume la posibilidad de imitar pari passu el modelo clásico de desarrollo capitalista occidental. Ello implica ente todo un olvido de las profundas diferencias de situación histórica entre el proceso capitalista de Europa Occidental y Estados Unidos, y el que eventualmente se proyecta y busca para América Latina. Olvida además las radicales diferencias de contexto internacional, especialmente el papel decisivo de la relación de dependencia a que está sometida la región $y$, por lo tanto, los obstáculos externos que se oponen al desarrollo económico, el cambio social y la autonomia y democratización políticas.

En segundo lugar, supone y exhibe una concepción parcializada y banal del subdesarrollo y del desarrollo, en términos puramente economicistas. El subdesarrollo parece limitarse a ciertos factores y rasgos: estrangulamiento externo, predominio de la producción primaria, atraso industrial. La perspectiva y el proyecto del desarrollo privilegian lo puramente econó-

5Para una certera critica a ciertas concepciones vigentes sobre desarrollo, ver Sergio Bagú, "Necesidad de adoptar el desarrollo económico a la realidad social y politica", en l.a Gaceln, publicación del Fondo de Cultura Económica, México, junio 1963, p. 5. 
Marcos Kaplan / Corporaciones públicas multinacionales para cl desarrollo... mico, escamotean los aspectos y niveles sociales, ideológicos y psicológicos, sus correlaciones e interacciones, el carácter complejo y global del proceso. Ello es particularmente visible en lo que a la integración respecta. Aquélla desencadenaria el desarrollo económico y tecnológico que, actuando a su vez como agente autónomo y exógeno, operaria sobre el resto de la totalidad social, la transformaria, la modernizaria y racionalizaria, le aportaria la democratización interna y la autonomia externa.

En tercer lugar, en la presentación del modelo único para el desarrollo y la integración se ignoran otras fórmulas posibles. No se definen precisamente el significado y el contenido de la integración, el sistema de valores que se adopta, las alternativas que se enfrenta $y$ las opciones que se realizan, los objetivos y los medios, los requisitos internos y externos, los agentes y las resistencias, los instrumentos y las consecuencias.

Ese escamoteo es perceptible en lo que se refiere a los aspectos y niveles sociales, ideológicos y politicos, que parecen no existir o desempeñar un papel secundario en el proceso. Los enemigos del desarrollo económico y la integración no son ubicados ni caracterizados de modo inequivoco, ni se precisa qué se propone para vencer su resistencia. La responsabilidad de los grupos hegemónicos y de las clases dominantes en la situación latinoamericana a superar resulta oscurecida, o bien se la considera como mero subproducto del atraso que desaparecerá con éste. Es ignorada la necesidad de romper el vinculo de dependencia externa de América Latina y de modificar su ubicación subordinada dentro de un bloque sometido a los Estados Unidos. Las relaciones con esta última potencia son planteadas bajo el supuesto de una armonia preestablecida de intereses ${ }^{6}$.

Correlativamente, poco o nada se hace para precisar que clases y grupos fundamentales pueden - actual o potencialmente- promover y asegurar un proceso global e ininterrumpido de desarrollo e integración; cuáles serian sus modos de estructuración y acción, el reclutamiento de sus liderazgos, la formulación y articulación de sus motivaciones, actitudes e ideologias, su contribución a la dinámica de cambio y al logro de un consenso masivo y operante para los objetivos propuestos. No se hace ningún esfuerzo para determinar qué grupos pueden y deben asumir la hegemonia en el proceso ni de qué modo se repartirán los costos, sacrificios y beneficios. Entre el binomio desarrollo-integración y los cambios sociopoliticos, la disociación

"Ver James Petras, "La armonia de intereses, jdeologia de las naciones dominantes". en Kevista Desarrollo Económico, Buenos Aires, julio-diciembre ig66, Vol. 6, N.os 22-23. 
reina. No se promueve, y por el contrario parece temerse, los cambios profundos en la estructura social y en la constelación de poder que sustentan a las clases hoy dominantes. Una y otra no son cuestionadas, se las considera normales e innocuas, o bien se espera su modificación en sentido democratizante por el mero progreso del desarrollo económico y de la integración. No se elabora una real estrategia politica para el desarrollo y la integración, con determinación de alternativas, ideologias movilizadoras, formas y fases sucesivas. Las implicaciones y consecuencias de un proceso ininterrumpido de desarrollo e integración, la imagen de, la sociedad que emergería de aquél y que se busca como proyẹcto histórico, no aparecen por ninguna parte. La ideologia subyacente o explicita que se esboza no basta para proporcionar la movilización intelectual, emocional y práctica de los protagonistas posibles. Las disrupciones y violencias previsibles según la experiencia histórica en procesos de este tipo, son ignoradas o relegadas como manifestaciones patológicas e indeseables que debe excluirse a priori y a cualquier precio. Los esquemas, institucionales que se sugiere resultan abstractos y formales, desconectados del contexto global y carentes de base y de operatividad.

El modelo propuesto queda recluido a la vez en la Utopia y en la Ucronia. No demuestra sus ventajas, ni persuade sobre los peligros de su frustración. No se enraiza en las élites dirigentes ni en las masas, no logra su adhesión ni las constituye en base de consenso para las grandes decisiones y las acciones transformadoras. Asi' lo demuestran los aspectos y resultados de su funcionamiento concreto.

Como consecuencia del juego de fuerzas y circunstancias que se ha indicado precedentemente, cada pais ha tendido a considerar su desarrollo económico como empresa exclusivamente nacional y autárquica; a proteger indiscriminadamente las ramas y empresas de su propio ámbito, especialmente las industrias antiguas e-incipientes, sin preocupación de eficiencia y de posibilidades futuras. Varios paises de la Zona se han lanzado desde hace años a crear industrias clave (siderurgia, automotores). Ello ha significado antieconomicidad por desperdicio de recursos escasos, y desconocimiento de las economias de escala. Sobre todo, ha creado poderosos intereses que podrian obstaculizar el avance y la vigencia real de la integración; $y$ ha agravado el dilema "región-nación"; replanteado en este caso entre la preocupación de conservar posibilidades de industrialización nacional y el otorgamiento a ésta de un espacio económico satisfactorio para una gran producción racionalizada. Algunos paises no creen que su espacio econó- 
Marcos Kaplan / Corporaciones públicas multinacionales para cl desarrollo...

mico sea insuficiente. Otros temen que la cooperación económica regional, funcionando exclusivamente en base al veredicto de rentabilidad impuesto por el simple juego del mercado, destruiria sus propias industrias en provecho de los paises mayores de la Zona, o los mantendria en su actual status de pais no industrializado.

La integración regional ha sido aceptada sólo por imposición de las circunstancias, con toda clase de reservas mentales y prácticas, con un enfoque limitativo y un procedimiento de insuficiencia y lentitud cada vez más perceptible. No se ha comenzado por grandes lienamientos y objetivos. El esquema concebido para la integración es el de una Zona de Libre Comercio. Se limita por consiguiente al campo meramente mercantil. Tiende a liberalizar el intercambio a través de negociaciones periódicas, destinadas a rebajar o suprimir tarifas y restricciones al tráfico reciproco, a crear preferencias comerciales entre miembros del grupo. Se imponen nada más que obligaciones restringidas, que lo confian todo a un simple juego de la competencia en un mercado ampliado, con un minimo de intención planeadora subsidiaria. No se trasciende la etapa de simple cooperación por acuerdos limitados para el cumplimiento de objetivos de interés común, con total conservación de las soberanias originales y relaciones laxas, restringidas y carentes de dinamismo ininterrumpido. No se exige ni impone cambios estructurales en todos los aspectos y niveles de la economia, de la sociedad y del sistema politico, ni la creación consiguiente de un desarrollo sostenido $y$ autónomo. Todo ello ha impedido resolver los problemas de desequilibrio y estancamiento que no han tardado en plantearse.

Las tarifas son disminuidas mediante un procedimiento gradual $y$ selectivo, de micronegociaciones producto por producto, y rebajas minimas anuales por promedios del conjunto de aranceles aplicados en la Zona. El sistema resulta a la vez demasiado rigido y demasiado flexible. Por una parte, cada pais negocia sobre miles de productos, considerados uno por uno, con los restantes, y luego todos juntos en tratativas generales. Por otra parte, cada pais es libre entonces de fijar el cómo, el cuándo y el monto de la reducción de gravámenes para cada producto. Todo ello condiciona los avances de la integración a la solúción de los conflictos generados por là confrontación de los intereses creados de cada pais con los del resto de la región. Permite que grupos reducidos frenen la adopción de medidas integradoras. Cada pais actúa en definitiva con el permanente temor a ceder 
demasiado, a que el costo concreto de la integración exceda más de lo conveniente a los beneficios que, además, parecen en general remotos y abstractos y están sujetos a controversia. Existe siempre el deseo de aprovechar unilateralmente los beneficios de la integración en beneficio de la propia nación; asi como la consiguiente falta de generalidad y reciprocidad en lo que a estos beneficios respecta. No hay certidumbre sobre cuándo y hasta dónde se producirán y se mantendrán las desgravaciones. Se dificulta la determinación real y concreta de la situación en que quedarán en definitiva ciertos productos, impidiéndose asi el aprovechamiento de las concesiones y la efectiva programación de inversiones públicas y privadas.

Agrava más aún las dificultades el hecho que, desde hace ya varios años, la casi totalidad de los paises de la ALALC sufren una situación de franco estancamiento económico. Ello da mayor rigidez a sus .estructuras y reduce su capacidad para ajustarse dinámicamente al proceso de cambio. En consecuencia, se tiende más aún a considerar ALALc como lugar de colocación de sobrantes de las producciones nacionales, derivadas del estancamiento o del menor ritmo de crecimiento. No se crean o aprovechan economias de escala. El intercambio de productos industriales se vuelve dificultoso. Una vez más se revela cómo, si bien la integración es un medio para el desarrollo, la falta de un desarrollo rápido y efectivo paraliza o dificulta enormemente las tareas de la integración.

El mecanismo de integración ha carecido hasta ahora de estructuras institucionales adecuadas. Los órganos creados por el Tratado no están capacitados para ejecutar eficazmente las tareas ampliadas que requiere una nueva etapa de integración. Ellos representan y defienden ante todo los intereses de.cada pais - a través de gobiernos que tampoco suelen ser demasiado representativos-, lo que dificulta la subsistencia de un interés sostenido por el progreso de la integración. No se trata todavia de instituciones responsables ante la comunidad, dotadas de atribuciones e instrumentos capaces de formular y cumplir una politica de integración y desarrollo regionales.

El proceso concreto de la ALALC ha comenzado a exhibir sintomas de estancamiento. En las primeras negociaciones se avanzó rápidamente, pero a partir de niveles muy bajos, en relación a productos ya comercializados tradicionalmente en la Zona, o cubiertos antes de i 960 por convenios bilaterales que establecian desgravaciones especiales; y-respecto de.los cuales sólo se trataba de renegociar o consolidar. Algunas concesiones tarifa- 
Marcos Kaplan / Corporaciones públicas multinacionales para el desarrollo...

rias han sido meras reducciones de tasas teóricamente altas, pero no aplicadas. Los paises de tasas altas, han estado en mejor situación que otros para reducir tarifas, sin que ello equivaliera a una reducción real de la protección.

Los éxitos iniciales de las negociaciones se produjeron en cuanto a materias primas y productos agropecuarios en los cuales cada pais se siente eficiente y competitivo, o sobre productos de importancia tradicional desde terceros paises. Las dificultades han comenzado cuando se ha debido negociar y conceder sobre articulos que ya tienen producción actual significativa o expectativas próximas de tenerla en el pais otorgante, y que pueden ser importados desde la región a precios internacionales; especialmente productos industriales (bienes de consumo final, metalurgia liviana, vehiculos, maquinarias poco complicadas): Ha habido también dificultades en cuanto a productos cuya importación se controla o prohibe en defensa de la balanza de pagos. Asi, ha resultado cada vez más dificil incluir en las negociaciones $y$-desgravaciones a la mayoria de los productos del arancel, precisamente los susceptibles de intensificar y diversificar el intercambio.

Puede mencionarse por último otros obstáculos que operan en el mismo sentido. Existen diferencias de estructuras y niveles de los aranceles aduaneros, regimenes monetarios y crediticios, y además instrumentos de la politica económica; en los grados de productividad, tasas de salarios y sistemas de previsión social. "La distinta composición de las.importaciones que cada pais realiza desde la zona y la ya mencionada facultad que tienen los paises para seleccionar los productos que negocian y' la reducción de gravámenes que lés acuerdan, significa que no todos comprometen los mismos articulos $y$, además, que la rebaja aduanera $y$ la preferencia son por el común distintas. Hasta que no entre en vigor la Lista Común I973, nada asegura a los productos incorporados al programa de liberación un tratamiento aduanero uniforme". En consecuencia, no se garantiza: trato ni margen de preferencia iguales para todos los productos; y "no existe un mercado regional para casi ninguno de los productos ya incluidos en el programa de liberación. Apenas se abren oportunidades, con grados diversos de efectividad real, en alguno o algunos de los presuntos paises importadores'" Al ser dificultosos el cálculo de promedios ponderados de derechos y gravámenes de efecto similar, y la comprobación del cumplimiento de compromisos minimos por parte de los paises, la negociación se

7 Hacia la Integración Acelerada..., cit. pp. $84-85$. 
ES TU DIOS I N T ER NA C I O NALE S

basa "fundamentalmente en el establecimiento a priori de un cierto equilibrio de oportunidades", lo que contribuye a no estimular el aumento del número y del alcance de las concesiones que un pais está dispuesto a otorgar.

En materia aduanera, monetaria, cambiaria, crediticia y financiera, los paises de la ALALC mantienen una heterogeneidad y disparidad de regimenes que también inciden negativamente en el proceso de integración.

A las diferencias de tarifas aduaneras debe agregarse la existencia de múltiples trabas en los regimenes de licencias, depósitos previos, recargos fiscales, que no suelen ser materia de negociación, y respecto de los cuales el Tratado ha dejado vias de escape. No se han hecho progresos significativos hacia la creación de una tarifa común hacia terceros paises.

Prácticamente todos los paises integrantes de'la ALALC sufren el estrangulamiento de sus sectores externos, la inestabilidad permanente de sus reservas de oro y divisas, y una inflación casi ininterrumpida. La inflación particularmente contribuye a dificultar el crecimiento; corroe cualquier esfuerzo tendiente a elevar el nivel de ahorro público y privado; determina violentas fluctuaciones en los costos y en la productividad; impone frecuentemente una coexistencia de politicas de estabilización formal y de desvalorización real. La anarquia monetaria interna que resulta de ello se refleja en el proceso de integración. La inflación, y la heterogeneidad y anarquia de los regimenes monetarios, dificultan adicionalmente el aumento del comercio intrazonal, y sobre todo la incorporación al mismo de los bienes industriales. Las fluctuaciones en niveles de productividad y costos que son su consecuencia, inciden en la inestabilidad y en el carácter contradictorio de las politicas cambiarias; multiplican las sobre y las subvaluaciones, $y$ toda clase de artificios cambiarios. El principio de reciprocidad, esencial en la mecánica del Tratado, se ve afectado en sus mismas bases, ya que las disparidades monetarias y' cambiarias y sus múltiples efectos limitan la vigencia de las reducciones tarifarias y de los acuerdos de complementación.

Se carece también - sobre todo por la presión opositora del Fondo Monetario Internacional, del Banco Mundial y de los Estados Unidos- de instrumentos de compensación de intercambios, excedentes $y$ déficit financieros, para las relaciones bilaterales y multilaterales entre los miembros de la Zona, y entre ésta y el resto del mundo, necesarios para superár las continuas crisis y para preparar un régimen de plena convertibilidad y 
Marcos Kaplan / Corporaciones públicas multinacionales para el desarrollo. .

una unión monetaria en el seno de la alalc. Tampoco, y por las mismas razones, se ha logrado crear sistemas de financiamiento para el planeamiento industrial regional y para las empresas de integración.

La falta de uniformidad de las politicas crediticias de los Estados miembros crea ventajas competitivas para aquellos que otorgan facilidades especiales a sus exportaciones. De modo similar ven reforzadas eventualmente sus posibilidades de competencia los paises en ‘que rigen más bajas tasas de salarios y regímenes más restrictivos de previsión social.

Los paises de la Zona adolecen de agudas insuficiencias en la tasa de formación del ahorro público y privado; y en la asignación.de recursos suficientes y esenciales para actividades productivas y proyectos de.integración. Prevalece la inçomunicación entre los mercados financieros y de capital de la Zona, y es débil, o inexistente, la capacidad de negociación de ésta frente a los paises y organismos internacionales proveedores de fondos.

Por el impacto convergente de los factores y circunstancias que se ha señalado, los sintomas de crisis y estancamiento de la ALALC se han venido multiplicando. El número de productos negociados en las sucesivas ruedas de desgravación tiende a reducirse. El comercio intrazonal crece lentamente. Se negocian dos acuerdos de complementación industrial solamente, entre empresas internacionales, y lọ mismos tienen resultados poco considerables. El intercambio de productos manufacturados no aumenta significativamente, y el impacto de la integración sobre el crecimiento industrial es reducido. Faltan empresas e inversiones multilaterales $y$ proyectos especificos para actividades estratégicas $y$ polo supranacionales. Se sigue careciendo de una politica común hacia las inversiones extranjeras. Resulta insignificante el avance en la intensificación del comercio reciproco y de la coordinación de politicas nacionales para la producción agropecuaria. La insuficiencia es también perceptible en lo que se refiere a la reorientación y expansión de la infraestructura.

\section{UN AGENTE PARA UNA N'UEVA ESTRATEGIA: La CORPORACIÓN PÚBLICA MULTINACIONAL}

El Tratado de Montevideo representó un punto de partida minimo y posible para iniciar la experiencia de integración latinoamericana, con la participación de los principales paises de la región. En tal sentido, por la función experimental y catalitica que ALALC ha desempeñado, por todo 
EST U D I O S I N T ER N A C I O N A L E S

aquello que realizó, e incluso por los obstáculos e insuficientes que ha revelado, sus aspectos positivos resultan indiscutibles.

Se ha constatado ya sin embargo que, en su forma actual, el sistema de la ALALC ha evidenciado graves insuficiencias $y$ limitaciones, $y$ ha entrado en una situación de crisis y estancamiento que no parece por el momento superar. Resulta forzoso ir más allá de la forma y etapa actuales, e ir abarcando, sucesiva o combinadamente, las reglas y elementos de la unión aduanera, del mercado común y de la integración o comunidad económica propiamente dicha. Ello supone y exige no abandonar en bloque los elementos del esquema correspondiente a la primera etapa, sino flexionarlo y completarlo, comenzando por medidas transicionales a corto y mediano plazos, pero sobre todo insertando todo en una nueva estrategia de desarrollo e integración a que luego se hará referencia más explícita.

Desde ya puede afirmarse que, junto con los elementos y mecanismos de una estrategia de integración global para América Latina, es posible y necesario crear y movilizar otros correspondientes a estrategias y tácticas parciales, que no contradigan a la primera y general, y que por el contrario la enriquezcan y refuercen ${ }^{3}$. Tales estrategias y tácticas parciales deben consistir básicamente en proyectos multinacionales concretos tendientes a crear y a mantener operativamente centros y polos de acción integracionista, que la susciten, difundan y multipliquen en todos los niveles y dimensiones posibles, a través de los espacios, sistemas y grupos circundantes, dependientes o influidos. Más especificamente, la principal función concreta seria la de provocar efectos y movimientos de solidaridad real, de fuerte efecto multiplicador, y con el más alto grado posible de participación de múltiples espacios, sistemas, grupos e individuos; que provoquen y estimulen nuevas tentativas integradoras, se incorporen a la dinámica general de la integración, la preparen, refuercen y prolonguen. Este tipo de acción integracionista posibilita, al mismo tiempo, la disponibilidad de un instrumento conceptual, analitico y operativo; da una vigencia más concreta y real a la necesidad, conveniencia y viabilidad de la integración para los paises, regiones y grupos de ella implicados; afianza las integraciones sectoriales; crea economías de escala; permite un mejor uso de los recursos materiales, financieros y humanos; puede contribuir a la reducción de las diferencias en el grado de desarrollo entre los participantes de la

${ }^{8} \mathrm{Ver}$, -hacia una Estrategia de los Polos de Integración", en wTaL, Boletin de la Integración, marzo de 1966, Buenos Aires. 
Marcos Kaplan / Corporaciones públicas multinacionales para el desarrollo...

ALALC, y por lo tanto un mayor grado relativo de equilibrio entre los mismos.

A tales efectos es necesario comenzar por establecer qué tipos o categorías de relaciones posee - potencial o efectivamente- el mencionado potencial subintegrador; cómo estructurarlos en sistemas genéricos y proyectos especificos de gran efecto multiplicador; cuáles son sus condiciones concretas (económicas, sociales, institucionales, politicas, culturales) de factibilidad. Entre las muchas posibilidades al respeto, y como mera ejemplificación, puede señalarse algunos tipos de polos de subintegración: agrupaciones subregionales (Gran Colombia, Cono Sur, Cuenca del Plata, Grupo Andino); integraciones sectoriales (industrias básicas o dinámicas, infraestructura); integraciones fronterizas; programas y proyectos multinacionales especificos. En lo que sigue se discute la posibilidad de las corporaciones públicas multinacionales, su estructura y problemática, como agente y polo de desarrollo e integración.

\section{La integración de sectores públicos}

El Estado, el sector público de la economia y sus empresas, pueden y deben cumplir un papel decisivo en el proceso de desarrollo y de integración latinoamericana.

La realidad y trascendencia de este problema surge ante todo de la sostenida tendencia que el proceso latinoamericano exhibe en las últimas décadas, en el sentido del avance del intervencionismo estatal, del sector público de la economia y de las empresas gubernamentales. A partir de las primeras décadas del siglo $\mathrm{xx}$, pero sobre todo desde i $93^{\circ}$ en adelante, este proceso se perfila y acelera cada vez más acentuadamente, en función de una serie de factores, entre los cuales cabe mencionar: el debilitamiento de los mecanismos tradicionales de crecimiento en superficie, por estimulos externos y acción puramente privada; la nueva fase de urbanización e industrialización aceleradas; la emergencia de nuevos grupos sociales con fuerte impulso ascensional (capas medias, proletariado industrial); los cambios sustanciales en las relaciones de fuerza vigentes en la economia y en la politica mundiales, con implicaciones internas directas para América Latina; el replanteo del esquema de obtención y de ejercicio del poder politico; la afirmación de un clima colectivo de tipo nacionalista que va subrayando la importancia de los factores internos y la necesidad de instrumentos y mecanismos adecuados para promover la organización racional y la 
expansión de una economía independiente; la resistencia al cambio de las estructuras y grupos tradicionales; la inorganicidad, debilidad y falta de dirección de los sectores teóricamente interesados en modificaciones estructurales y en la modernización (empresariado industrial, movimiento obrero). Todo ello contribuye à determinar la expansión del intervencionismo estatal y del sector público, como elementos capaces de compensar o de suplir, en todo o en parte, el debilitamiento de los factores tradicionales de crecimiento; y de promover cierto desarrollo con la urgencia impuesta por el estancamiento y crisis de la estructura tradicional ${ }^{9}$.

De este modo, en los principales paises de América Latina, el Estado ha ido aúmentando: el número $y$ la envergadura de sus intervenciones y agencias de todo tipo, para la regulación orientadora, la promoción deliberada $y$ la participación directa en formas $y$ actividades de la economia y de la vida social que se consideran de interés público. Ha contribuido asi decisivamente a la emergencia de un tipo de economia mixta, caracterizado por la extensión creciente del control público y la pluralidad de los centros de decisión. Manifestación señalada de este proceso es la multiplicación del número y de la envergadura de acción de las corporaciones públicas de desarrollo y de financiamiento, de los departamentos de la administración central, de las sociedades comerciales del Estado, de las empresas públicas propiamente dichas, y de los entes mixtos. Abundan los datos, que no se transcriben aqui por falta de espacio, sobre el alto grado de participación del sector público en los gastos e inversiones totales; en la formación $y$ : distribución del producto bruto interno $y$ del ingreso; en el capital nacional; en el desarrollo de la infraestructura y de las industrias de bases; en las transacciones de bienes y servicios; en la absorción del crecimiento de la fuerza de trabajo; en el subsidio a consumidores y productores individuales a través de precios y tarifas de nivel reducido; en el sostén de la capacidad adquisitiva del mercado $y$ en la regulación de su estructura $y$ funcionamiento; en suma, en el desarrollo de las economias nacionales a partir de estimulos y mecanismos internos.

Lo expuesto es de por si revelador de la importancia que el sector económico y las empresas del Estado pueden adquirir para el proceso de integración, pero no agota la argumentación, que es reforzable a través de las consideraciones siguientes. Debe recordarse el papel que las iniciativas gubernamentales han tenido en la génesis y avance del Mercado Común

9 Ver bibliografia citada en nota 4 . 
Marcos Kaplan / Corporaciones públicas multinacionales para el desarrollo...

Europeo. El Estado tiene una aptitud natural para imponerse sobre estrechos particularismos regionales y sectoriales. Todo poder supranacional debe partir y pasar a través de los Estados nacionales existentes.

El sector público de los Estados latinoamericanos puede y debe además desempeñar un papel decisivo en la unificación de las politicas económicas, elemento esencial en el progreso de la integración regional. Puede contribuir por si mismo, a través de su participación - a menudo exclusiva - en sectores y ramas importantes (transportes, comunicaciones, electricidad, petróleo, industrias básicas); y de hecho algunas de las principales formas de cooperación internacional han emanado del sector público. A éste cabe además ejercer una función de contrapeso o de poder compensador de los acuerdos privados que tienden a buscar y obtener una posición de monopolio, y competir con las empresas particulares en el tejido de sólidos e irreversibles lazos socioeconómicos. La cooperación de los sectores públicos estaria destinada a desplegarse en tareas tan esenciales como la integración de infraestructuras, la creación o consolidación de industrias clave, el progreso de la tecnologia teórica y aplicada, la planificación regional (fronteras, cuencas de rios internacionales). Los sectores públicos pueden, finalmente, contribuir a la armonización de las politicas de coyuntura (monetaria, crediticia, bancaria), social (empleo y sus condiciones; estatuto común para trabajadores del Estado, que podria ir siendo adoptado como modelo.por el sector privado); el acercamiento general de legislaciones ${ }^{10}$.

La convergencia operativa de sectores públicos debe producirse como parte y dentro del marco de planes regionales de inversión para las principales ramas económicas de América Latina en que aquéllos operen, que prolonguen y armonicen los respectivos planes nacionales, y contribuyan a generar, mediante el logro de beneficios tangibles para las partes, la comunidad de propósitos y la solidaridad duradera de intereses de los paises. participantes, entre si y con la región en su conjunto. Más particularmente, se supone que ello contribuirá a establecer actividades económicas en común y corrientes persistentes de intercambio que resulten favorables al crecimiento equilibrado de los paises a integrar. Contribuirá también al surgimiento de una nueva geografia socioeconómica y politica, promovida de modo deliberado y consciente, a través de: la fusión y propagación de la,

${ }^{10}$ Ver André Marchal, L'Europe Solidatre, Editions Cujas, Paris, 1965. 
E S T U D I O S I $\cong$ T ER $\therefore$ A C I O $\therefore$ A L E S

ciencia y la tecnologia; el estimulo de las especializaciones y de la multilaterización del tráfico intrarregional; la superación de desequilibrios y distorsiones; la incitación a la interdependencia entre los paises; la creación de hábitos de cooperación; .. la superación de rígidos marcos fronterizos, adaptándolos a las realidades socioeconómicas.

Este tipo de colaboración a través de los sectores públicos puede corresponder a una experiencia similar a las de coproducción que han comenzado a darse en los últimos años. Aquélla se define y caracteriza, para el modelo que se discute, por los siguientes rasgos ${ }^{11}$ :

Asociación contractual entre centros públicos de decisión y producción, correspondientes a distintas naciones y sistemas, en virtud de lo cual se ponen en común aportes especializados en condiciones definidas, a fin de alcanzar ciertos objetivos, mediante acciones mancomunadas, y compatibilizadas.

Vinculación institucional y duradera de intereses y de procesos productivos $y$ de intercambio, entre centros de decisión constituidos por representantes del interés general (Estado, entes públicos descentralizados).

Instalación de la unidad coproductora como consecuencia de acuerdos internacionales que, o bien sólo admiten la posibilidad de alentar la creación y de conjeturar sus condiciones generales, o bien se comprometen ya en una situación especifica.

Definición, en el acto de creación del proceso y ente de asociación, de un cierto número de condiciones: modo de establecer planes, programas y proyectos; financiamiento; aporte; posición respecto a los mercados; distribución de resultados financieros; modalidades de reinversión.

Sin perjuicio del objetivo común a los dos o más conjuntos o centros de decisión que participan, cada uno de ellos conserva finalidades y lógicas propias. La coproducción a través de sectores públicos no puede dejar de ser, por un periodo histórico imprevisible, terreno de concursos y de conflictos. Puede dar lugar a conjunciones de poderes mutuamente reforzados, como a tensiones por enfrentamientos de poderes contrapuestos. Por otra parte, surge $y$ se afirma al mismo tiempo un compromiso entre los diferentes planos y series de intereses de los Estados, de sus economías y sociedades nacionales. La experiencia debe por lo tanto tomar en cuenta los objetivos

${ }^{11}$ Maurice Byé, "Cooperación en la Producción y Convergencia en los Sistemas Económicos", y R. Demonte, "La Coproducción", en i.TAL, Boletin de la lnlegración, Buenos Aires, julio de ig66 y marzo de 1967 , respectivamente. 
Marcos Kaplan / Corporaciones públicas multinacionales para el desarrollo...

de sus asociados, nunca contradecirlos. Su estructura y su funcionamiento, las secuencias de propagación que genera o refuerza, necesitan ser compatibilizadas con las condiciones generales de desarrollo de los paises participantes.

El importante problema de indole general que inmediatamente se plantea es el de la constitución de unidades capaces de afrontar tareas de desarrollo e integración regionales, conformadas como empresas comunes - multinacionales que, dentro de los limites preindicados, gocen de un cierto grado de autonomía orgánica y funcional. Tales unidades pueden basarse en una participación y un aporte de tipo puramente privado, o puramente público, o en una combinación de ambos. Son posibles por consiguiente soluciones múltiples: empresas puramente privadas; empresas privadas, pero ligadas contractualmente con administraciones públicas; empresas mixtas, en parte públicas y en parte privadas, ligadas o no por contratos con administraciones públicas; empresas intergubernamentales $y$, en este último caso, formadas sólo por Estados latinoamericanos, o también con participación de Estados extrarregionales. Este trabajo propone la forma de empresa multinacional formada por Estados latinoamericanos, por considerarla como la más conveniente y viable para la cooperación integradora ${ }^{12}$.

\section{Una gama de posibilidades}

Debe observarse ante todo que se plantea a este respecto una amplia gama de posibilidades. Puede ocurrir que los gobiernos participantes se propongan, en la experiencia de cooperación, no multiplicar entes independientes y evitar cargas y complicaciones financieras, juridicas y administrativas. En este caso, una organización internacional preexistente puede asumir la nueva tarea, aportar las facilidades materiales requeridas, administrar la actividad o la empresa como "programa especial" o "acuerdo especial". Puede ocurrir también que, sin crear una nueva persona juridica, los Estados participantes instituyan a una administración nacional como

${ }_{12}$ Ver: Paul Reuter, Organisations Européemnes, Presses Universitaires de France, Paris, 1965; Louis Cartou, Organisations Européenes, Dalloz, Paris, 1965; Claude-Albert Colliard, Institutions Internationales, Dalloz, Paris, 1966; Carlos Fligler, "Multinational Public Enterprises", International ,Bank for Reconstruction and Development, June 1967 . Edición mimeografiada); "Creación de Empresas Multinacionales", en INTAL, Bolelin de la Integración, agosto de 1966. 
ES T U D I O S I N TE, R $\therefore$ A C I O $\therefore$ A L E S

encargada de la ejecución del proyecto en común, actuando la misma como agente colectivo de aquéllos y por cuenta de los mismos (contrato de "agency").

Por otra parte, es posible que se busque crear una persona juridica para dar a la cooperación de los Estados un cuadro permanente y autónomo. En este caso, la tarea o proyecto determina en gran medida el tipo y la estructura de la organización. Si la actividad encarada se traduce finalmente sólo en textos (estudios, informes, resoluciones, proposiciones), el ente no requiere más que un aparato similar. al de cualquier administración nacional (secretariado permanente, consejo de represeritantes de los Éstados nacionales). Por el contrario, se requerirá una organización operativa de mayor desarrollo y complejidad si se trata de la gestión de una empresa o de instalaciones importantes, que implican y requieren una amplia gama de actividades (abarcadas además en el ámbito de aplicación de las leyes nacionales de varios Estados), un volumen considerable de sus gastos e ingresos, una multiplicidad de relaciones con particulares, empresas privadas y colectividades públicas.

Esta forma se ha ido multiplicando, en número y envergadura, durante los últimos años. Aparecen bajo denominaciones diversas empresas públicas multinacionales, compañias internacionales, empresas comunes, corporaciones internacionales, establecimientos públicos internacionales. Se trata de estructuras predominantemente económicas, más que politicas, que pueden operar en campos y actividades tan diversas como: la creación, la construcción y/o la gestión y operación de infraestructuras e instalaciones productivas, o la prestación de servicios públicos. Más especificamente, transporte aéreo, terrestre, fluvial y maritimo, caminos; comunicaciones; otros servicios públicos; industria (acero, petroquimi-. ca, maquinaria pesada); combustibles y energia; obras hidráulicas, educación; investigación científica y teconológica; sanidad, aumento y diversificación de la producción agropecuaria y minera para abastecer el mercado regional; reforma agraria y colonización (Esta es una enumeración puramente ejemplificativa). En general, se trata, como se ve, de actividades y tareas que exigen cuantiosos recursos humanos, materiales y financieros, provenientes de varias fuentes nacionales, y mercados considerables; para planes, programas y proyectos a largo plazo y de naturaleza pública; y que requieren ser asumidas por una organización pluri- 
Warcos Kaplan / Corporaciones públicás multinacionales para el desarrollo... gubernamental permanente, creada por varios Estados, con posibilidades operativas, y poderes $y$ medios de acción directa ${ }^{13}$.

Se requiere en efecto, a tales propósitos, agencias de competencia territorial coextensa con las áreas y actividades implicadas, en función de programas y proyectos multinacionales. Tales entes deben estar dotados de autonomia orgánica y funcional, y combinar el goce de facultades gubernamentales con un alto grado de libertad, flexibilidad, iniciativa, posibilidades de riesgo e innovación, lo que torna inconveniente todo lo que implique la rigidez, la cautela y la rutina tipicas de las administraciones públicas tradicionales. Las empresas públicas multinacionales deben estar aseguradas contra la influencia de consideraciones y presiones puramente nacionales, politicas $y$. de grupos privados. $A$ ello se agrega la posibilidad de atraer y conservar una élite gerencial y un personal capaces, de espiritu emprendedor e identificado con los objetivos y exigencias del desarrollo y de la integración regionales. La autonomia es requerida asimismo para lograr una participación de varios Estados que permita balancear sus intereses y fines e impida el logro de ventajas especiales para uno de ellos solamente en detrimento de los demás. Empresas de este tipo facilitarian la obtención de asistencia financiera de agencias y organismos internacionales, ya que permiten combinar el aporte de garantias por los Estados participantes con las ventajas de una gestión coherente por una dirección unificada $y$ de una simplificación en la administración $y$ supervisión del préstamo y del programa o proyecto en cuestión.

\section{Siluaciones y estructuras institucionales y juridicas}

Las empresas públicas multinacionales surgen por acuerdo de dos o más Estados, socios en las empresas comunes. (Puede admitirse la hipótesis de

13Ver: Konstantin Katzarov, Teoria de la .Vacionalización (El Estado y la Propiedad), Instituto de Derecho Comparado, México, 1963; William A. Robson, L'Industria Nazionalizzata e la Propietá Pubblica, Edizioni di Comunitá, Milán 1962; Nationalization - A Book of Reading Edited by A. H. Hanson, George Allen and Unwin Lid., Londres, I963; Le Fonctionnement des Enterprises . Vationalisées en France - Travaux du 3e. Colloque des Facultés de Droit, Dalloz, Paris, 1956; Pierre Bauchet, Proprieté Publique et Planification (Enlerprises Publiques .Von Financieres), Editions Cujas, Paris, 1962; A. H. Hanson, Public Enterprise \& Economic Development, Routledge \& Kegan Paul Ltd., Londres, 1959; Ingnacy Sachs, Paltems of Public Sector in L'nderdeveloped Economies, Asia Publishing House, New York, 1964; Marcos Kaplan, Paises en Desarrollo y Empresas Ptiblicas, Editorial Macchi, Buenos Aires, 1965 . 
que se acepte también la participación de entes públicos autónomos de los respectivos paises). Este acuerdo implica la elaboración de un régimen internacional especial, que puede reflejar distintas situaciones y concretarse en diferentes estructuras institucionales $y$ juridicas. El acuerdo cristaliza en un tratado, convención o acuerdo, otorgado de conformidad con los procedimientos básicos de cada Estado (v. gr., con o sin autorización legislativa), y que se vuelve asi el instrumento constituyente básico de la empresa pública multinacional. La solución a que se llegue debe tomar en cuenta una serie de circunstancias concretas, tales como: despliegue de las principales actividades y tareas de la empresa pública multinacional en un solo Estado, o en varios; mayor o menor peligro de que uno de los Estados influya o controle excesivamente el ente y sus operaciones; etc. En primera aproximación general, puede constatarse que la fórmula elegida comienza por definirse en función del instrumento constituyente, la ley a regir, la personalidad y capacidad juridicas, y la nacionalidad de la empresa pública multinacional.

Una serie de variantes puras y combinadas son posibles al respecto:

El Tratado compromete a los Estados participantes solamente para la creación de una empresa común, fija su objeto, su marco de operaciones, las obligaciones y derechos de los gobiernos. La creación misma de la empresa, la finación de su estructura y funcionamiento y de la ley que la rija, el otorgamiento de personalidad y capacidad juridica y de nacionalidad, pueden estar contenidas como estatutos detallados en un protocolo adicional al Tratado, o en convenciones posteriores.

El Tratado crea directamente la empresa, y establece para ella la ley aplicable, la personalidad y capacidad juridica, la nacionalidad, la estructura y las modalidades de funcionamiento. A partir de esta variante, $y$ en relación a dichos aspectos, se abren varias posibilidades, sobre todo las siguientes:

El tipo o categoria de empresa que se elige proviene del sistema juridico de uno de los Estados participantes. Aquélla es establecida como empresa nacional de ese Estado que le otorga sede, personeria juridica reconocida plenamente por los otros Estados socios, la rige por su ley nacional aplicable a otras empresas públicas en lo referente al status y a sus asuntos internos.

El instrumento constituyente mismo crea la empresa y la somete a un régimen internacional; fija el tipo o categoria de aquélla; es la ley aplica- 
Marcos Kaplan / Corporaciones públicas multinacionales para el desarrollo...

ble con exclusión de toda otra ley nacional; le otorga personalidad y capacidad juridica internacionales dentro de los territorios de los Estados signatarios. La nacionalidad es la de todos y cada uno de los Estados participantes.

En todos y cada uno de los aspectos mencionados pueden darse soluciones y variaciones combinatorias. Algunas de las soluciones a dichos aspectos pueden estar contenidas en un instrumento separado, protocolo 0 anexo del Tratado. El instrumento constituyente puede establecer que ciertas modificaciones serán introducibles en el futuro sin necesidad de ratificación por los parlamentos nacionales. La personalidad y la capacidad juridicas del ente pueden tener carácter internacional, no por el instrumento constituyente, sino de manera objetiva ( $v$. gr., por necesidad funcional para el cumplimiento de los fines propuestos, o por el elevado número de los Estados miembros). La personalidad juridica puede ser otorgada, no por el Tratado o por uno de los Estados participantes, sino por cada uno de éstos, o bien aquélla es dada por uno o varios Estados y la empresa pública multinacional resulta gobernada por una ley nacional con ciertas restricciones derivadas del Tratado. La ley vigente puede ser la de un Estado, con algún grado de restricción o modificación proveniente del Tratado; o al revés, el instrumento constituyente fija su propia prelación y la aplicación subsidiaria de una ley nacional.

Las empresas públicas multinacionales suelen presentar muchos rasgos de las empresas públicas y privadas nacionales. Sin embargo, el hecho de ser creadas por, o como consecuencia de, un tratado, con la consiguiente combinación de elementos a la vez estatales e internacionales, modifica en ciertos casos y aspectos los resultados que tales rasgos tendrian bajo una ley y dentro de una ámbito puramente nacionales. Particularmente, la función asignada determina la esfera de la jurisdicción y la amplitud de los poderes requeridos para su efectivo cumplimiento.

Considero conveniente adoptar, con las modificaciones requeridas, el prototipo de la corporación pública, que William A. Robson califica como "la más importante invención del siglo $\mathrm{x}$ en el campo de las instituciones públicas. . destinada a desempeñar en la industria nacionalizada del siglo $\mathrm{xx}$ un papel tan importante como el de la empresa privada en el ámbito de la organización capitalista del siglo $\mathrm{xIx}^{\prime \prime}$. Sus caracteres, adaptados a las condiciones regionales especificas en que debe operar, y los problemas que pueden suscitarse, son a grandes rasgos los siguientes. 
El tratado constitutivo debe crear la corporaciôn pública multinacional CPM, fijar su tipo y su objetivo, la ley que la gobierne, la personalidad y la capacidad juridicas, la nacionalidad. Debe establecer además, al menos en grandes lineas, su estructura, sus funciones $y$ modalidades operativas, sus derechos y obligaciones y los de los Estados participantes, su patrimonio y privilegios, las relaciones con los gobiernos y con otras empresas públicas y privadas. La reglamentación detallada de los aspectos vinculados directamente con la estructura y el funcionamiento puede efectuarse a través de protocolos y anexos del Tratado original, convenciones posteriores, estatutos. El Tratado debe determinar quiénes, y de qué manera, pueden dictar normas reglamentarias y complementarias, incluso sin necesidad de acuerdos diplomáticos de igual categoría que el constituyente. Debe precisar también el modo de solución de los posibles conflictos entre el instrumento constituyente y las leyes nacionales de aplicación subsidiaria.

Las disposiciones sobre los aspectos indicados se refieren sobre todo a la personalidad y capacidad juridicas de la CPM dentro de los territorios de los Estados signatarios. Fuera de ellos, la personalidad y capacidad juridicas de la CPM están determinadas por el alcance que se reconozca a su carácter de sujeto internacional y por las facultades que surgen de su status original. Su personalidad internacional puede no ser reconocida, por terceros paises. Estados, entes públicos y empresas privadas de terceros paises pueden aceptar el establecimiento de relaciones juridicas con la CPM (compraventa, locaciones de servicios y de obras, préstamos). A ello se agregan los problemas derivados de la responsabilidad de los Estados participantes por la actuación de la CPM fuera de sus territorios, y del derecho de aquélla a una posible protección diplomática. La situación se complica por el hecho que ni los instrumentos constituyentes ni el Derecho Internacional Público en su desarrollo actual están en condiciones de prever todas las situaciones eventuales y contingentes que pueden emerger de la actividad de una CPM, ni existen tampoco tribunales internacionales de jurisdicción obligatoria a tales efectos. Para las relaciones entre la CPM y los terceros paises, sus Estados y particulares; debe aplicarse necesariamente los principios y reglas sobre conflictos de leyes del Derecho Internacional Privado. 
Marcos Ḱaplan / Corporaciones públicas multinacionales para el desarrollo...

La CPM tiene un fin público. Es instrumento común de los Estados nacionales participantes, $y$ se inserta en el sector público de la economia de aquéllos. Por consiguiente, la CPM reúne y fusiona actividades; tareas y entes que ya pertenecen a los sectores públicos de los paises participantes, o que son incorporados a éstoș especialmente para la experiencia integradora a intentar. La incorporación puede producirse por diversos mecanismos: expropiación, nacionalización con o sin estatización, confiscación (por aplicación de norma penal o por acto revolucionario), socialización. Las decisiones sobre la incorporación y sobre la concurrencia a la creación de la CPM, se efectúan de acuerdo a las normas y procedimientos correspondientes a cada uno de los Estados participantes.

La creación de la CPM no implica necesariamente una amplia transferencia de soberania, sino la estructuración de una autoridad y de una politica conjuntas para un sector, programa o proyecto. La CPM debe si constituir un ente independiente, con personalidad $y$ capacidad, autonomia administrativa, responsabilidad propia, derecho a comparecer en juicio como actor demandado; amplios poderes de decisión en materia de gestión económica y financiera, contabilidad, patrimonio, adquisición $y$ disposición de bienes y servicios, manejo de personal, contrataciones en general. Las finalidades buscadas y las funciones a cumplir contribuyen a la fijación de los poderes requeridos para su logro y del ámbito en que deberán ser ejercidos. Esta fijación de poderes puede estar expresada en el instrumento constituyente y sus complementos y reglamentaciones, o surgir porinferencia de ellos y de las finalidades y funciones atribuidas al ente. Los Estados signatarios pueden además comprometerse a la adopción de aquellas medidas (legales, financieras, fiscales, aduaneras, patrimoniäles) que faciliten las operaciones normales de la CPM.

La cPM por una parte se halla aparentemente separada de los Estados que la crean, con personalidad propia e independencia relativa. Por otra parte, sin embargo, sigue orgánicamente ligada a los Estados que concu, rren a crearla y utilizarla, sometida a su control y con responsabilidad frente a ellos. La ligación con y el control de los Estados participantes se originan y ejercen a trayés del hecho mismo de la creación de la CPM por aquéllos; de la elaboración y modificación de instrumentos constituyentes y sus complementos; de la participación en el capital accionario y del voto en las asambleas generales de accionistas; del nombramiento. $y$. 
E S T U D I OS I N T ER NA C I O NALE S

remoción de directores. Este control debe unificarse en algún tipo de agencia supranacional con representantes de los Estados interesados.

Este control por la rama ejecutiva de los Estados asociados debe cumplirse sobre las cuestiones más importantes, especialmente las que hacen a la politica general, $y$ a los asuntos de especial importancia, $y$ siempre en materias precisamente determinadas - globalmente o en detalle- por el Tratado y/o la ley vigente. No es conveniente en cambio que existan supervisión ni limitaciones a priori en lo referente a las actividades normales ni a las cuestiones administrativas comunes de la empresa.

$\mathrm{Al}$ control por los ejecutivos nacionales pueden agregarse otros: parlamentario, judicial, financiero, de eficiencia, por órganos de planificación. Algunos aspectos de las operaciones de la cPM pueden ser colocados bajo el control de un cuerpo externo, ya existente o creado al efecto, donde tengan representación los Estados socios.

En general es obvia la necesidad de reglamentar precisa y adecuadamente los órganos y procedimientos de supervisión y control.

La CPM debe contar como es lógico con sus propios órganos de dirección y gestión. Estos pueden ser: una asamblea que reúna a los accionistas (Estados, entes públicos autónomos) o sus equivalentes; una junta supervisora externa como la mencionada más arriba; un presidente; una junta de directores o consejo de administración; un gerente general o director administrativo. El presidente, los miembros de la junta o consejo, deben ser nombrados por acuerdo de los gobiernos y para un número determinado de años. El gerente general o director administrativo puede ser nombrado en las mismas condiciones, o bien por la asamblea de accionistas y/o la junta o consejo.

Los instrumentos constituyentes y sus complementos y reglamentaciones deben precisar las funciones y poderes de los diferentes órganos, y las relaciones de éstos entre si y con los Estados participantes. El problema es particularmente grave, sobre todo si se recuerda que la.cPM es por una parte relativamente autónoma respecto a los Estados nacionales, sus provincias y órganos locales, y por otra parte está insertada en los respectivos sectores públicos y debe mantener una amplia gama de relaciones de todo tipo con aquéllas y con los aparatos politico-administrativos de los paises asociados.

En todo caso, es indispensable que los órganos directivos y de gestión gocen de independencia, de protección frente a las vicisitudes politicas $y$ a 
Marcos Kaplan / Corporaciones públicas multinacionales para el desarrollo...

las presiones de grupos privados, $y^{\prime}$ que tengan una amovilidad limitada a casos especiales taxativamente enumerados $y$ con garantia del derecho de defensa.

La CPM debe tener un amplio margen de libertad para fijar el estatuto de su personal diferente del que rija para los funcionarios y empleados públicos en el sentido estricto tradicional; ello es así, tanto para el presidente, el consejo directivo y los altos funcionarios, como para los cuadros medios, empleados y obreros. No debe existir en principio contralor ni decisión prioritaria de los gobiernos en la fijación de las condiciones de remuneración, reclutamiento, despido, régimen de servicio, disciplina. La CPM debe gozar de entera libertad al respecto.

La selección de los directores de los cuadros intermedios y del personal de base, debe tender a la captación de elementos calificados, con el más alto grado posible de devoción a los fines públicos, de desarrollo e integración de la cPM y tratar de reclutarlo én principio entre los nacionales de los Estados miembros, guardando cierto equilibrio en la distribución por origenes, pero sin hacer de este último criterio una norma absoluta y excluyente. El tipo de personal y el estilo de gestión pueden constituir uno de los factores que más efectivamente coadyuven a la emergencia y el refuerzo del proceso de desarrollo e integración de América Latina.

El instrumento constitutivo y sus complementos deben efectuar una determinación detallada en cuanto a las lineas generales de funcionamiento de la CPM. Por otra parte, ésta debe gozar una amplia independencia en cuanto a la gestión económica, patrimonial y financiera. Ello plantea una serie de complejos problemas, de solución nada simple.

Es imprescindible ante todo que el instrumento de creación defina desde el principio, al menos en sus términos básicos, un cierto número de condiciones: modo de establecer planes, programas $y$ proyectos; financiamiento; distribución de los aportes, de los mercados y de los beneficios; modalidades de inversión. Una dificultad ineludible y decisiva surge del hecho que la cPm suele ser formada por paises de nivel de desarrollo y potencial económico desiguales. La actividad de la empresa común absorbe recursos de todos los países participantes, pero puede favorecer a una nación, región o rama más que a otras. Se trata de lograr modos operativos que permitan asegurar una cierta proporcionalidad y equilibrio de sacrificios y beneficios entre los paises concurrentes a la empresa común. 
Los aportes de los participantes pueden consistir en: recursos naturales y materiales; tierras y edificios; infraestructura; mano de obra; financiación; ciencia y tecnologia; información; mercados. El financiamiento, en particular, puede provenir de fuentes propias de la CPM misma (precios y tarifas de los bienes que produce $y$ servicios que presta); o externas a ella: aportes y préstamos gubernamentales; reserva del producto de ciertos impuestos en favor de la empresa común; préstamos y créditos de oțras corporaciones públicas; emisión de valores para el público; recurso al mercado monetario y al crédito bancario; autorización a la CPM para contraer deudas por sobregiro u otras causas; instituciones internacionales o gobiernos extranjeros.

La distribución de los frutos de la empresa es problema que requiere un doble enfoque. Por una parte, la cPM puede estar obligada a ceder totalmente los beneficios que obtenga a los Estados participantes; o bien, una vez pagadas sus obligaciones, incluso adelantos de los gobiernos y otros entes, impuestos, etc., puede disponer libremente de los beneficios de acuerdo a las facultades que le son propias (reinversión, aumento de sueldos y primas al personal). Por otra parte, los gobiernos participantes pueden acordar diversos modos de distribución de los frutos: participación en los beneficios, en los bienes producidos y servicios prestados, en los mercados, o en una combinación de los tres.

La. CPM debe tener un patrimonio propio, pero su contenido y alcance pueden ser variables. En una concepción restrictiva, que considero inconveniente, el conjunto del patrimonio de que dispone la CPM no pertenece a ésta, como persona juridica distinta, sino a los Estados participantes en proporción a sus aportes, que resultan los verdaderos titulares. La CPM sólo tiene el uso y usufructo del patrimonio y la actividad, y el derecho a su explotación; posee fondos de circulación y operación para enfrentar tareas y. compromisos. Los Estados autorizan la disposición de bienes, fijan condiciones y limites al empleo del patrimonio. Pueden incluso privarla total o parcialmente, en cualquier momento, del patrimonio, o incrementarlo, todo sin influencia real de la CPM sobre estos cambios. Por el contrario, dadas las finalidades y modalidades de la CPM, es preferible que ella disponga de un patrimonio en, el más amplio y libre sentido de la palabra, dentro del marco general que fija su régimen.

La base patrimonial y las finanzas de la cpm deben ser autónomas, separadas de los presupuestos nacionales ordinarios, a los que. en principio no 
Marcos Kaplan / Corporaciones públicas multinacionales para el desarrollo...

deben ingresar los beneficios. Por su fin público, si bien este tipo de ente es creado para actuar como industrial, comercial, prestador de servicios, con tendencia a la autosuficiencia financiera, no puede ni debe operar sólo por el incentivo del simple logro de beneficios, como una empresa privada cualquiera, sino como sujeto y custodio de los intereses generales de los paises participantes y de la región. Debe tender a la obtención de ingresos iguales o superiores a los egresos; y en caso de existir excedentes, los destinará a reinversiones, reservas, rebajas de precios, mejoras de la eficiencia y de las condiciones de remuneración y trabajo. La administración de los fondos de reserva debe corresponder a la CPM, sin perjuicio de las directivas generales que los gobiernos, o el órgano común de supervisión y control, dicten al efecto. De todos modos, la norma debe ser el autofinanciamiento de la empresa pública multinacional, mediante la cobertura de los gastos corrientes y de inversión con los propios ingresos. Puede asimismo, como ya se dijo, recurrir a créditos y subsidios de gobiernos o de organismos internacionales, y a empréstitos públicos. Si lanza titulos al mercado general de capitales, sus tenedores no tendrán voz ni voto en los asuntos del 'ente. En general, la búsqueda de un balance entre los fines socioeconómicos ${ }^{\circ}$ politicos de la CPM y los fines de rentabilidad y autosuficiencia financiera, las opciones a efectuar entre las alternativas de gestión deficitaria, constituyen una de las cuestiones centrales de la estructuración y dinámica de este tipo de ente.

Se plantean finalmente varios problemas especiales que deben ser mencionados, aunque su análisis escape al ámbito de este trabajo:

La CPM puede y debe recibir privilegios e inmunidades; que se relacionarán con los objetivos, las necesidades operativas y el grado de independencia acordada, asi como con el equilibrio entre los Estados participantes y entre los intereses nacionales en juego. Los privilegios e inmunidades pueden referirse a: estatuto tributario (exención total o parcial de impuestos); liberación de derechos aduaneros y de otras restricciones, en cuanto al tráfico entre paises participantes de materias primas, bienes de capital, equipos, para instalaciones y operaciones de la CPM, y en cuanto a los bienes y servicios que ella produce, trafica y presta; supresión de trabas sobre la compra, tenencia y uso de divisas, y sobre las transferencias de fondos; protección a la propiedad de la empresa (especialmente, garantias contra requisas, expropiaciones y confiscaciones); responsabili- 
dad hacia los Estados, otros entes públicos y particulares, dentro del ámbito territorial propio y fuera de él.

Sometimiento o exención respecto a las normas reguladoras de libre competencia o represivas del monopolio.

Organos y procedimientos jurisdiccionales de interpretación y de solución de controversias, entre los Estados participantes, entre éstos y la CPM, entre ésta y empresas públicas y privadas, y con respecto a gobiernos y particulares de terceros paises, En lo que al órgano respecta, puede tratarse de: un tribunal de conciliación previa; un tribunal independiente ya existente o creado al efecto; un ente arbitral especial; un experto de emergencia dotado de poderes decisorios.

Entrada en vigor del instrumento constitutivo; terminación y liquidación de la CPM.

La CPM puede tener diferentes ámbitos y alcances de actuación. Así, por una parte, puede ser concebida y puesta en funcionamiento como corporación general de desarrollo, y en tal caso sus funciones más importantes serian: estudiar los aspectos de las economias nacionales de los paises que la forman o de la región común a que se destina su actividad; coordinar y dar coherencia a los esfuerzos de desarrollo; lograr y movilizar capital para financiar planes, programas y proyectos, y realizarlos directamente - mediante creación de empresas públicas secundarias, participación en sociedades mixtas, promoción de empresas privadas, con distintos tipos de aportes (capital, crédito, ayuda técnica y administrativa); comprar y vender materiales y equipos de producción y servicios.

Puede tratarse en otros casos de corporaciones de promoción y financiamiento para ciertas ramas industriales, agropecuarias y de servicios; o de administraciones para asumir y ejecutar programas de desarrollo integral de cuencas fluviales. Desde otro punto de vista, puede tratarse de corporaciones públicas multinacionales destinadas a operar en todo el ámbito de los paises participantes en una experiencia de integración (v. gr., Corporación Andina creada por el Acuerdo de Bogotá), o bien solamente para ciertas ramas o regiones.

No es ocioso advertir finalmente que la teoria pura y la legislación formal referidas a este tipo de entes, pueden resultar desvirtuadas en la práctica, y en dos direcciones opuestas: la supercentralización burocratizante por ingerencia excesiva de los gobiernos participantes, o las rivalidades $y$ conflictos entre ellos por el control de la corporación; y la auto- 
Marcos Kaplan / Corporaciones públicas multinacionales para el desarrollo... nomia excesiva, generadora de dispersión, irresponsabilidad y anarquia. La experiencia de muchos paises demuestra que es difícil dar contenido real y operatividad a la intención y a la letra de la legislación, asi como seguir un camino diagonal equidistante entre autonomia y control, entre iniciativa y uniformidad. Que sea dificil no significa que resulte imposible. Aqui aparecen cuestiones de indole más general, a que se hace breve referencia en las conclusiones siguientes.

\section{CONCLUSIONES: BALANCE Y PERSPECTIVAS}

La corporación pública multinacional es propuesta como uno de los agentes, instrumentos y mecanismos que pueden participar en un proceso combinado de desarrollo e integración, promoverlo y reforzarlo. Al mismo tiempo, las posibilidades que la CPM cumpla real y eficientemente esta función están determinadas y condicionadas también por lo que ocurre con ese desarrollo y esa integración. La interacción entre lo que puede ocurrir con las CPM y el proceso real de desarrollo e integración es fácilmente perceptible. Si las primeras pueden coadyuvar al segundo, también es cierto que los Estados latinoamericanos y sus sectores públicos evidencian una serie de fallas y limitaciones a que ya antes se hizo referencia. Esto, unido a la resistencia de las fuerzas y estructuras tradicionales, pueden impedir el surgimiento o el eficaz funcionamiento de las CPM O convertirlas en meros injertos modernizantes dentro de realidades que no llegan a modificar y que provocarán su inoperancia y fracaso. No es ocioso subrayar que el presente y el futuro inmediato se plantean a este respecto en términos de alternativas y opciones, de tipos de modelos y procesos posibles. A riesgo de esquematizar y caricaturizar, y forzado por los limites de estructura y espacio de éste trabajo, es dado afirmar que se presentan dos posibilidades básicas ${ }^{14}$.

\section{El modelo vigente}

Por una parte, el proceso latinoamericano puede continuar, durante un periodo histórico de duración imprevisible, según los lineamientos segui-

${ }^{14}$ Con relación a los modelos de desarrollo e integración, dentro de la abundante literatura al respecto, puede verse: Obstacles to Change in Latin America - Ediled by Claudio Veliz, London-New York-Toronto, Oxford University Press, 1965; The Politics of Conformity in Latin America - Ediled by. Claudio Véliz, Oxford University Press, 1967; Latin America, Reform or Revolution - A Reader edited by James Petras and Maurice Kcitlin. Fawcett Publications Inc., Greenwich, 1968; además de las obras citadas en la nota I. 
dos en las últimas décadas, presuponiendo por consiguiente la subsistencia y el funcionamiento irrestricto de un sistema de propiedad, iniciativa y ganancia privadas, el libre juego de las fuerzas de mercado y la situación de dependencia externa. En tal caso, es posible que prosiga y se logre en cierta medida un tipo particular de desarrollo y de integración, que presentarán rasgos muy especiales. Tendrán lugar en el interés, por el impulso y bajo el control de las grandes corporaciones internacionales de capital norteamericano y del gobierno de los Estados Unidos. Se cumplirán de acuerdo a un esquema de nueva división internacional del trabajo que se elabora en y para beneficio de la metrópolis, privilegiando ciertas clases sociales, ramas económicas y regiones de los paises latinoamericanos, en desmedro de las restantes. La hegemonia de los consorcios y del Estado norteamericanos se ejercerá cada vez más sobre los aparatos más importantes de producción, comercialización y financiamiento; sobre las poblaciones y los mercados; sobre la selección, la elaboración y el uso de la ciencia y de la tecnologia. En la medida que un proceso de esta indole y sus resultados y secuelas implican congelar o rechazar los cambios sociales profundos, generarán una amplia gama de tensiones y conflictos. La hegemonia de los Estados Unidos deberá ejercerse por consiguiente a través de un control absoluto de los aparatos politicos y militares, y la represión totalitaria se convertirá en modelo casi exclusivo de organización y equilibrio sociales. Los centros de decisiones se transferirán cada vez más a la metrópolis. América Latina deberá incorporarse definitivamente, mucho más que hasta el presente, a un sistema de interamericanismo satelizante. Los actuales paises de la región perderán no sólo los restos. de autonomia real que aún gozan, sino los prerrequisitos minimos para la viabilidad nacional (aunque se conserven algunos atavios externos de una independencia puramente formal). El resultado será una integración cumplida — según certera expresión de Antonio Garcia-, desde afuera $y$ desde arriba, $y$ un desarrollo dependiente, deformado, multiplicador de distorsiones $y$ desequilibrios entre paises, regiones, sectores económicos y clases sociales.

\section{L'n modelo alternativo}

Por otra parte, una alternativa opuesta parte de la premisa que la integración es de todas maneras irreversible e ineludible, y que debe evitarse 
Marcos Kaplan / Corporaciones públicas multinacionales para el desarrollo... su cumplimiento desde afuera y desde arriba. Ello supone y exige la elaboración y ejecución de una estrategia que exprese y sirva un modelo concreto, basado a su vez en una concepción global y unificada del desarrollo y de la integración, en todos los aspectos y niveles (económicos, sociales, ideológicos, culturales), y con interacción de ambos términos como partes inescindibles de un proceso único, a cumplirse desde adentro y desde abajo. Las transformaciones estructurales profundas en lo interno y la integración regional deben suponerse, entrelazarse y fortalecerse reciprocamente. Más concretamente, debe determinarse con precisión y realismo:

Qué sistema de valores se adopta, como base y criterio para la toma de decisiones frente al espectro de alternativas, para la fijación de prioridades y metas, para el rechazo del modelo propuesto hasta ahora, y para la creación y adopción de otro modelo alternativo.

La elaboración y difusión de una ideologia capaz de proporcionar el esquema intelectual, los criterios orientadores, el estimulo a la movilización intelectual y sociopolitica de los grupos dinámicos y renovadores $y$ de las mayorias nacionales, el sacudimiento y transformación de partidos politicos y de las instituciones.

Cuales son los intereses y las fuerzas, los beneficios y los agentes, actuales y potenciales, del desarrollo y de la integración que se busca, la gravitación relativa de aquéllos, sus posibilidades y modos de articulación, alianza y liderazgo. Cuáles son los enemigos, y cómo neutralizarlos o. anularlos.

Objetivos, condiciones, métodos e instrumentos del desarrollo y de la integración. Escalonamiento en etapas. Exigencias, requisitos y consecuencias. Cambios sociales concomitantes y resultantes. Tipos de economia, de sociedad, de régimen politico, de estructura institucional, de cultura $y$ de ubicación en el sistema internacional, que se busca y se prevé como resultante del proceso.

Para un desarrollo y una integración de América Latina a realizar desde adentro y desde abajo, debe comenzarse por cumplir, con espiritu critico e inventivo, el análisis y el diagnóstico de los problemas que se enfrenta, la formulación y ejecución de soluciones ajustadas a las realidades propias y a las condiciones especificas de los paises de la región, con pautas originales y sin imitación de fórmulas importadas. Ello implica un plan, y por lo tanto una estrategia concebida como un cuerpo más o menos cohe- 
rente de decisiones, sobre un conjunto de opciones económicas, sociales, politicas, ideológicas y culturales.

América Latina necesita una politica unificada que asegure: un gran y rápido impulso de desarrollo; la promoción simultánea de la transformación estructural $y$ del aumento de productividad del agro $y$ la mineria, $y$ de una industrialización que supere la etapa de mera sustitución de importaciones; la redistribución progresiva del ingreso; la independencia económica nacional, que no excluya sino posibilite la integración regional; la prioridad de la acumulación nacional, y el papel subsidiario y estrictamente controlado de capitales y apoyos externos; un mayor equilibrio entre las regiones. El desarrollo económico debe estar acompaniado por cambios sustanciales en la estructura social; un mayor grado de igualdad y justicia socioeconómicas; la distribución pareja de esfuerzos, sacrificios $y$ beneficios; modificaciones en la actual correlación de status y poder entre las clases y grupos; el sacudimiento de la apatia e indiferencia de las masas y el estimulo a su apoyo y a su participación activa $y$ directa; la democratización integral de la economia, la sociedad, el Estado y la cultura. El aleatorio y errático crecimiento económico bajo un régimen más o menos liberal debe ser reemplazado por un desarrollo total a todos los niveles, inducido por el Estado y otros organismos en la medida en que operen como auténtica representación de las mayorias nacionales, a través de un plan cada vez más imperativo. Los Estados latinoamericanos, en efecto, pueden ser agentes valiosos de desarrollo e integración en la medida en que sean profundamente modificados en su contenido sociopolitico $y$ en su estructura administrativa. El objetivo y la justificación de esta estrategia se reducen, en última instancia, a la creación de estructuras económicạs, sociopoliticas y culturales que satisfagan con la mayor plenitud posible las crecientes necesidades de la población $\nvdash$ garanticen a sus miembros la expansión de su personalidad y de sus capacidades.

En la medida que se cumplan estos procesos y se llenen estos requisitos, ello contribuirá a posibilitar y reforzar las condiciones y exigencias de la integración misma, tales como las siguientes:

Control creciente de los sistemas de poder y de decisión por grupos dinámicos y transformadores, que no teman. y resistan la integración y por el contrario la necesiten y promuevan.

Obtención de un grado cada vez mayor de articulación nacional interna $y^{\prime}$ 
Marcos Kaplan / Corporaciones públicas multinacionales para el desarrollo...

de consenso más o menos generalizado a favor del desarrollo y la integración, como base para la actuación en ese sentido por Estados representativos, consolidados y eficaces.

Ajuste reciproco de estructuras $y$ mecanismos internos $y$ latinoamericanos. Viabilidad y eficacia de las politicas y planificaciones nacionales, y su creciente coordinación con otras de tipo regional, compatibilizadas con las primeras.

Creación más o menos gradual de autoridades supranacionales o comunitarias de decisión politica, planeamiento y acción diplomática.

Ruptura de la dependencia externa respecto a los Estados Unidos, al bloque latinoamericano bajo su hegemonia. Recuperación de la autonomia politica y diplomática. Elaboración y ejecución de una politica exterior latinoamericana, que permita la negociación unificada frente a los bloques internacionales y a las grandes potencias.

Desde un punto de vista más amplio aún, el modelo esbozado presupone $y$ pide la convergencia de tres órdenes de elementos:

Una alianza operativa de las clases y grupos de tipo más o menos dinámico y transformador: proletariado industrial, masas trabajadoras de la ciudad y del campo, intelectuales, profesionales, técnicos, pequeños $y$ mediana empresa nacional; y el logro gradual de una hegemonia dentro de esta constelación por los sectores más esencialmente predispuestos a la continuidad y profundización del proceso.

La aparición y afirmación de una vanguardia de cuadros politicos y administrativos, dotados de clara visión sobre los fines, las prioridades y los medios; de lucidez ideológico-politica y de eficiencia técnica; con devoción por el interés de la sociedad, la nación y de la región, y voluntad inquebrantable de llevar a cabo las tareas indicadas; $y$ prevenidos al mismo tiempo ante el peligro de convertirse en una élite privilegiada y alienada de sus propios pueblos, $y$ de promover un capitalismo burocrático de Estado que desvirtúe los objetivos buscados y frustre su logro.

Alto grado de conciencia, interés y participación directa y activa de las capas más amplias de la población en la búsqueda e imposición de los cambios y en la restructuración y manejo del Estado.

Este modelo alternativo, que aqui apenas se esbozal escuetamente, puede intentarse y cumplirse en la medida en que los equipos y clases que lo dirijan $y$ protagonicen comprendan que el desarrollo y la integración implican cambios rápidos, profundos y disruptivos en todos los aspectus y 
ESTLED IOS I $X$ TER $X A$ C I O NALES

niveles de las sociedades nacionales y de la región en su conjunto, a través de un proceso ininterrumpido y por un periodo histórico imposible de prever por anticipado. Ello trae aparejado la posibilidad cierta de conflictos entre grupos y poderes internos de América Latina y externos a ella, de convulsiones, cataclismos sociopoliticos y violencias. Aún más, el modelo puede, en principio y en teoria, darse durante un tiempo en los cuadros de una economia mixta. Por sus propias caracteristicas y por su dinámica inherente, en las condiciones y con las proyecciones señaladas, tiende a entrar en contradicción con un sistema de propiedad, empresa y ganancia privadas, $y$ a desembocar en un doble juego de opciones fundamentales: reforma o revolución, capitalismo o socialismo.

Ninguno de los dos modelos analizados tiene aseguradas a priori las posibilidades de triunfo y perduración. En la América Latina de hoy, como en todas partes y siempre, la Historia no tiene fatalidad ni fines predeterminados. Su orientación y sus alternativas son resultado de las acciones y relaciones de grupos e individualistas vivientes, en interacción de los determinismos, las voluntades conscientes y los azares. La confrontación de ambos modelos, la opción definitoria entre ellos, constituyen un elemento central de la honda crisis que vive América Latina, y será objeto ineludible de la praxis colectiva que se exigirá cada vez más de sus hombres $y$ mujeres en el presente y en la inmediata etapa histórica por vivir. 